Alma Mater Studiorum - Università di Bologna DEPARTMENT OF ECONOMICS

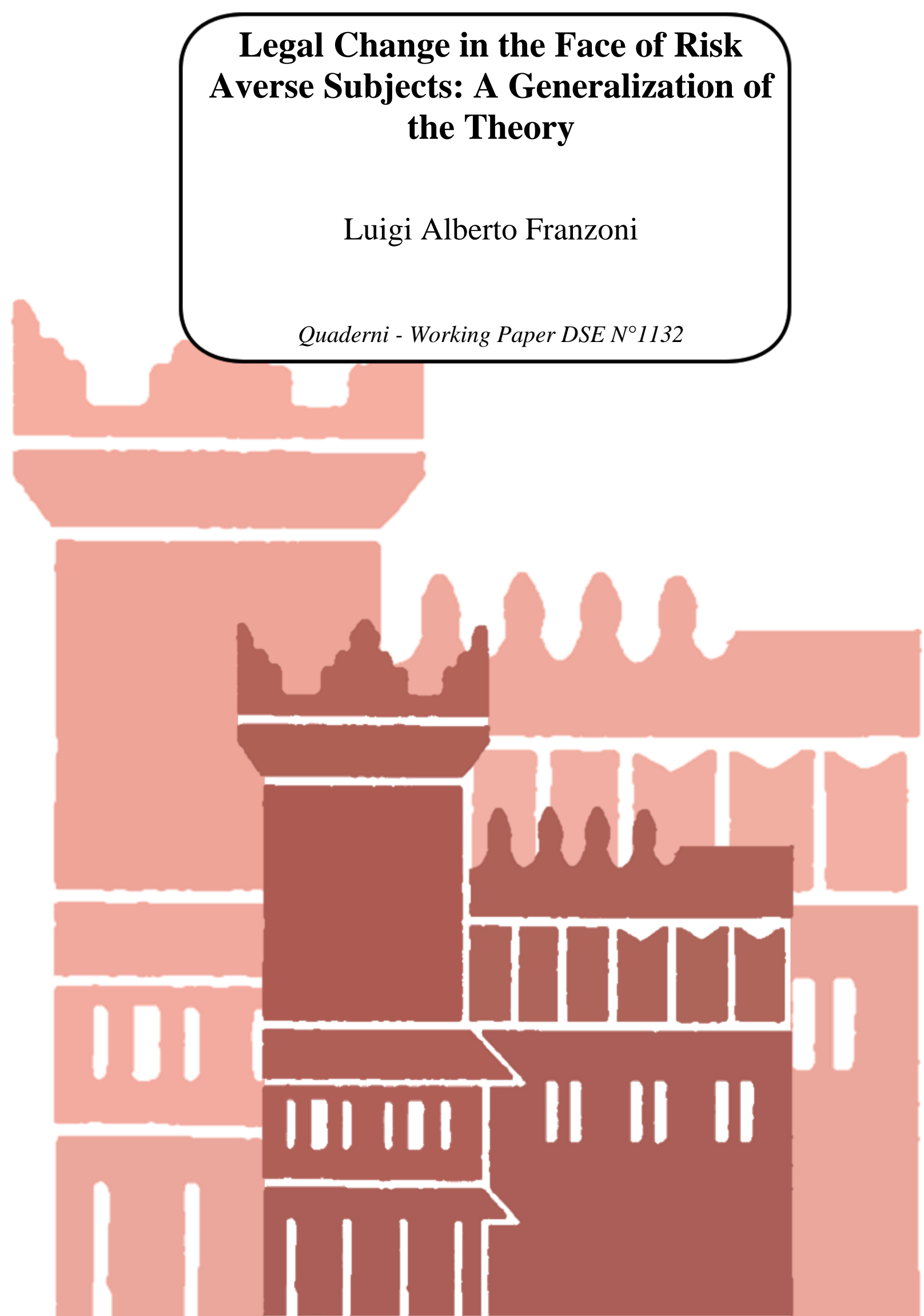




\title{
Legal Change in the Face of Risk Averse Subjects: A Generalization of the Theory
}

\section{Luigi Alberto Franzoni ${ }^{* \dagger}$}

\author{
May 2019
}

\begin{abstract}
This study investigates the optimal nature of law making under uncertainty. I focus on a case in which a harmful activity will be subjected to some regulatory measures (a standard, exposure to liability, or a corrective tax). The benefits and costs of precaution are ex-ante uncertain, and this places a risk burden on both injurers and victims. The optimal policy should, at the same time, strike a balance between benefits and costs of the measures, and attenuate the ex-ante risk. Whether measures should be made stronger or softer depends on the size and the sign of the shocks affecting the parties (positive or negative) and their disposition towards risk. With corrective taxes, it also depends on the elasticity of precautions with respect to the tax rate.

Keywords: legal change; regulation of risk; externalities; cost-benefit analysis; emerging risks.

JEL codes: K2 (Regulation and Business Law), D62 (Externalities), L51 (Economics of regulation)
\end{abstract}

${ }^{*}$ Correspondence to: Luigi A. Franzoni, Department of Economics, Piazza Scaravilli 2, 40126 Bologna, Italy.

${ }^{\dagger}$ I am grateful to Steven Shavell for very constructive comments. I would also like to thank Editor Albert Choi, two anonyomous referees, M. D'Antoni, T. Baker, A. Daughety, F. Fagan, C. Sanchirico, J. Teitelbaum, and seminar participants in Amsterdam, Bologna, Lleida, London, Milan, Philadelphia, and New York (Alea 2019). Part of this research was conducted when the author was visiting Penn Law School. 


\section{NON TECHNICAL SUMMARY}

From an economic standpoint, legal change is characterized by two distinctive features. On the one hand, it is largely unpredictable, as it is affected by a myriad of evolving factors, including political preferences, and economic and technological conditions. On the other, it is to a great extent uninsurable, as insurance companies tend not to cover losses due to variations in the law. The consequence is that legal change imposes costly risk on the people affected.

Take the case of environmental law. We know that climate change will call for drastic policy interventions, aimed at reducing the impact of the increased world temperature. The timing and the scope of these measures remain highly uncertain, as they depend, in addition to political preferences, on the evolution of the climate system and on technological breakthroughs. Older technologies might be outlawed, entire industries might disappear. At the moment, however, it is hard to make predictions about the path the law will actually take, and this places a huge dose of uninsurable risk on the shoulders of the companies and the individuals affected. Should this uncertainty impact on policymaking? If yes, what shape should policymaking take to mitigate the cost of uncertainty?

In this paper, I consider a specific tool that the government can employ to reduce the risk that legal change imposes on affected parties. This tool, called "attenuation," requires that the government introduces an insurance element in its policy making. Specifically, policy making should try and smooth out the welfare level of the parties affected. Measures that impose a costly burden on the parties should be made softer if parties have been hit by a negative shock, and they should be made harder if parties have been hit by a positive shock. Several applications of this tool are discussed. 
"This search for static security - in the law and elsewhere - is misguided. The fact is that security can only be achieved through constant change ..." Justice W.O. Douglas, Stare Decisis (1949).

\section{Introduction}

From an economic standpoint, legal change is characterized by two distinctive features. On the one hand, it is largely unpredictable, as it is affected by a myriad of evolving factors, including political preferences and economic and technological conditions. On the other, it is to a great extent uninsurable, as insurance companies tend not to cover losses due to variations in the law (see Shavell (2014b)). The consequence is that legal change imposes costly risk on the people affected.

Take the case of environmental law. We know that climate change will call for drastic policy interventions, aimed at reducing the impact of the increased world temperature. The timing and the scope of these measures remain highly uncertain, as they depend, in addition to political preferences, on the evolution of the climate system and on technological breakthroughs. ${ }^{1}$ Older technologies might be outlawed, entire industries might disappear. At the moment, however, it is hard to make predictions about the path the law will actually take, and this places a huge dose of uninsurable risk on the shoulders of the companies and the individuals affected. Should this uncertainty impact on policymaking? If yes, what shape should policymaking take to mitigate the cost of uncertainty?

This article addresses this fundamental normative issue by considering a traditional externality setup, in which an activity causes harm with a probability that depends on the precautions taken by some injurers. ${ }^{2}$ Other parties, called victims, bear the risk of

\footnotetext{
${ }^{1}$ Predictions about the climate trajectory are known to be plagued by extensive scientific uncertainty. Uncertainty also pertains to technological advancement, especially in the fields with strong environmental bearing like hydropower, solar PV, smart grids, battery storage, electric vehicles, concentrated solar power, biomass supply, biofuels, carbon capture and storage. Estimates of the marginal cost of reducing a ton a carbon dioxide in year 2050 , under a $+1.5^{\circ}$ scenario, range from $\$ 245$ to $\$ 14,300$ (see IPCC (2018), p. 152).

${ }^{2}$ As I will explain below, my paper heavily builds on Shavell (2014b).
} 
harm. At time zero, there is uncertainty about the actual probability of harm and the cost of precaution. This uncertainty will unfold at a later date (time 1), when a specific policy measure (e.g., a regulation mandating specific precautions) will be enacted. At time zero, both injurers and victims are subject to uninsurable risk, since they cannot predict with certainty the cost of complying with the regulation and the likelihood of harm. I investigate the impact of this uncertainty on social welfare and study how the policy measure should be designed to mitigate the risk burden of the affected parties.

In addressing these issues, I will expand on the results of Shavell (2014b). In his insightful contribution, he analyses a simplified version of the problem above (the activity at hand can only be harmful or not) and focuses on the ex-ante risk borne by the injurers. He shows that the government can reduce this risk by committing to "attenuate" the new policy measure: by making it less stringent than otherwise optimal, the government reduces the prospective compliance costs for the injurers and provides them with partial insurance. The attenuation of the policy measure provides a firstorder reduction in risk with only a second-order loss in terms of distorting the ex-post optimum.

I extend Shavell's fundamental results in two directions. First, I consider the possibility that parties are affected both by negative (as in Shavell's original contribution) and positive shocks. The latter case arises, for example, when the costs of precaution turn out to be smaller than expected, possibly because of a major breakthrough in prevention technology. Second, and more importantly, I consider the impact of uncertainty on the victims' welfare. Differently from injurers, who face uncertainty about the cost of complying with the new measure, victims face uncertainty about the ensuing probability of harm. Such an uncertainty, by itself, does not reduce the welfare level of the victims. ${ }^{3}$ By using an intuitive analytical approach, based on certainty equivalents, I am able to decompose the risk borne by the victims in two parts: the ex-ante risk (associated with the uncertainty about the probability of harm) and the ex-post risk (associated with

\footnotetext{
${ }^{3}$ Technically, victims face a "compound lottery," i.e. a lottery whose prizes are lottery tickets. For a rational agent, all that matters is the compound probability of winning: "... only algebra, not human behavior, is involved in this definition" (Samuelson (1952)).
} 
the prospect of harm, with a given probability). I show that efficiency considerations induce the policy maker to mitigate both the ex-ante and the ex-post risk. In fact, if the ex-ante risk of the victims is reduced, the expected amount of resources devoted to precaution goes down (and this is surely welfare improving if injurers are not averse to risk). The reduction in the ex-ante risk can be obtained by requesting injurers to take additional precautionary measures when the probability of harm turns out to be high, and fewer precautionary measures when the probability of harm turns out to be low. ${ }^{4}$

In general, the policy makers should pander to the ex-ante risk borne by both injurers and victims. So, the optimal attenuation policy might entail a stronger or a weaker measure than suggested by ex-post cost-benefit analysis. As I will show, the direction of the policy change will ultimately depend on a simple condition that accounts for: i) sign and size of the shocks parties are subject to, and ii) their disposition towards risk. For example, if all parties are equally averse to risk and injurers turn out to be particularly negatively affected, the optimal policy calls for a laxer measure (to reduce their compliance costs). Conversely, if victims are particularly negatively affected, the optimal policy calls for a stricter measure (to reduce the probability of harm).

Following Shavell (2014b), I apply the attenuation logic to three policy tools: 1) a regulation imposing a standard of behavior to limit harmful effects (this could be a command and control limit on emissions, a technology standard, or a negligence standard), 2) liability for the harm caused (a policy that enables victims to claim damages for the harm suffered), and 3) corrective taxation, i.e., taxes or subsidies encouraging the adoption of preventive measures.

With respect to regulation, I show that the standard should be lowered if: i) injurers are subject to a negative shock and victims to a positive shock, ii) both injurers and victims are subject to a negative shock, and victims are better able to take additional risk, iii) both injurers and victims are subject to a positive shock, and injurers are in a better position to take additional risk. A similar result applies to liability for harm. Damages should be reduced (with respect to the otherwise optimal level) if conditions

\footnotetext{
${ }^{4}$ Shavell (2014b) focuses on the case in which victims are either risk neutral or they can purchase insurance at a fair premium. So, the effect mentioned above does not arise.
} 
equivalent to those listed above apply. I also show that, in contrast to the classic result of Shavell (1982), here, optimal damages can exceed harm (when the injurer is subject to a positive shock).

The results for the taxation case are notably different. ${ }^{5}$ Here, an increase in the marginal tax rate affects the payoff of the injurers exclusively by means of variations in their tax payments. The increase in the marginal rate affects the victims through the reduction in harm brought about by the additional precautions exerted by the injurers. If precautions are very sensitive to the tax rate, the attenuation policy should target the victims.

While the three tools mentioned above are equally efficient when parties are indifferent to risk, they are not equivalent when parties are averse to risk, as I assume in this article. I show that when injurers are nearly risk neutral and victims risk averse, liability for harm is the most efficient tool. If victims are nearly risk neutral and injurers are risk averse, regulation and taxation fare better under a weak comonotonicity condition.

Literature review. My contribution touches on two distinct strands of the literature.

Legal change. One of the central tenets of recent law and economics literature is that parties who are negatively affected by a policy change should not be compensated. ${ }^{6}$ This perspective, notably advanced by Graetz (1977) and Kaplow (1986), is based on the idea that the government is in no better position than private companies in providing insurance to the parties. As no government insurance is provided against adverse market changes, no relief should be granted to those who are adversely affected by legal change. This view is postulated on the premise that policy making is the outcome of proper balancing of benefits and costs of change, so the costs borne by the parties are part and parcel of a socially desirable legal change. ${ }^{7}$

\footnotetext{
${ }^{5}$ Shavell (2014b) considers non-linear taxes that mimic liability law. I focus instead on linear taxes, in line with the current policy debate (see Sec. 5 below).

${ }^{6}$ The early literature, building on the contributions of Michelman (1967) and Feldstein (1976), argued instead that losses caused by unilateral acts of the policy maker (such as a property or a regulatory taking) have to be compensated, in order to not frustrate legitimate expectations and to promote reliance on the law.

${ }^{7}$ The latter proposition is in line with the standard efficiency-based approach of law and economics,
} 
While Kaplow's argument that insurance should be provided by the private market is theoretically convincing, it runs against a major practical obstacle: insurance policies do not normally cover losses resulting from changes in the law (see the ample discussion in Shavell (2014b)). This puzzling fact has attracted recurrent scrutiny. Several explanations have been provided, including moral hazard and adverse selection (Blume and Rubinfeld (1984)), pricing difficulties (Masur and Nash (2010)), and the correlated nature of the losses (Shavell (2014b)).

In current policy making, the lack of private insurance has originated an array of mitigation policies aimed at providing "transition relief" to adversely affected parties. These policies, temporary or permanent, include specific exemptions, waivers, subsidies, grandfathering, and phase-ins. ${ }^{8}$ Following Shavell (2014b), I investigate the case in which "transition relief" is directly incorporated in the policy change. Policy making includes an insurance component aimed at smoothing out the welfare level of the parties. ${ }^{9}$

Policy making under uncertainty. Over the last decades, great effort has been exerted to understand the implications of uncertainty on policy making. An influential literature, inspired by Weitzman (1974), investigates optimal emissions abatement policy when both marginal costs and marginal benefits of abatement are uncertain. ${ }^{10}$ In this paper, I also assume uncertainty about benefits and costs. However, in sharp contrast to the aforementioned literature, I assume that policy is state-dependent (it is

which follows cost-benefit analysis in positing that a policy move is desirable when compensation of losing parties is just "feasible." Compensation itself is not required, as it pertains to the province of equity.

${ }^{8}$ See, among others, Levmore (1999), Shaviro (2000), Nash and Revesz (2007), Masur and Nash (2010), Shavell (2014a), and Trebilcock (2014). These authors defend transition relief on the basis of a variety of arguments, including efficiency, incentives for socially desirable investments, governmental legitimacy, and fairness.

${ }^{9} \mathrm{I}$ do not investigate the relative desirability of the attenuation policy vis-à-vis other relief policies. If costless direct income transfers were available, clearly a direct tax/subsidy policy would dominate. I regard this option as not practicable, as it would imply that, anytime a standard is changed, affected parties (both injurers and victims) either receive a tax or a subsidy.

${ }^{10}$ Weitzman's contribution is part of the standard environmental economics toolkit. For a concise introduction, see Aldy and Viscusi (2014). A different strand of the literature focuses on the uncertainty due to random "mistakes" in the enforcement of the law (see, for instance, Kolstad et al. (1990)). The presence of such mistakes would not change the substance of my arguments. 
applied when uncertainty has unfolded). It follows that the implication of uncertainty is not a policy mistake (e.g., the standard is inefficiently set), but costly risk (risk averse parties bear the cost of not knowing in which direction uncertainty will unfold). ${ }^{11}$ So, policy decision making will be guided by the parties' disposition towards risk, as well as the shape of marginal costs and benefits of precaution.

The attenuation logic requires that the outcome of traditional cost-benefit analysis be amended so as to include some "stabilization" factors, aimed at containing the variance of the parties's welfare levels. ${ }^{12}$ In environmental policy, similar concerns have recently let to the proposal of specific mechanisms aimed at reducing the volatility associates with emission control policy (such mechanisms include safety valves, allowance banking, and collars). ${ }^{13}$ The policy debate has so far focussed on the costs that uncertainty places on those who sink resources in emission abatement. My results take both sides of the "market" into account, and highlight the value of attenuating also the risk faced by the victims.

Note, finally, that in contrast to much of the literature on legal change that focuses on the uncertainty about the policy measure itself, my paper focuses on the fundamental uncertainty that triggers the policy decision (uncertainty about the costs and benefits of the measure). From this perspective, "inaction" can create greater risk for society than "action" (hence the opening quote). Newfound harms or new terrorist threats represent negative shocks that should be mitigated by means of a tough policy stance - to an extent that goes beyond momentary balancing of benefits and costs. In this sense, this paper provides some justification to the over-reaction that normally follows

\footnotetext{
${ }^{11} \mathrm{My}$ model does not deal with the costs of irreversibly that would arise if prevention measures were taken before uncertainty unfolds and could not be reversed for free at a later time. Irreversibility and learning call for delay in law making (see, for instance, Parisi and Fon (2009), ch. 3). Shavell (2008) investigates the impact of retrofitting costs on optimal prevention policy. Dari-Mattiacci and Franzoni (2014) focus on the adoption costs borne by the injurers when the prevention technology changes.

${ }^{12}$ In most countries, cost-benefit analysis is supplemented by an evaluation of distributional effects (see, for example, EPA (2016) and EC (2017)). This paper argues that, for efficiency purposes, costbenefit analysis should account for the negative or positive shocks parties have been subject to. To be sure, attenuation does not promote redistribution across individuals but across contingencies.

${ }^{13}$ See, for instance, Aldy and Viscusi (2014), Aldy (2017), and references therein.
} 
public scares, in the vicious circle at the core of Justice Breyer's concerns (see Breyer (2009)).

The paper proceeds as follows. Sections 2 offers a simple illustration of the attenuation principle. Section 3 deals with the case in which the policy maker decides a standard of behavior for the injurers. Section 4 analyses the case in which potential injurers face liability for the harm caused. The policy maker decides the level of damages to be awarded to the victims (these damages can under- or over-compensate victims). Section 5 deals with corrective taxation. The tax payment, which can be negative (i.e., a subsidy), decreases with the level of precaution taken. It shares the features of a standard emission fee (such as a carbon fee). The three tools are compared in Section 6. Section 7 concludes.

\section{The attenuation principle}

Let us consider a basic illustration of the attenuation principle. Suppose that an injurer can take precautionary measures that reduce the probability that $n$ victims suffer harm of magnitude $h$. Let us further assume that the cost of precaution is ex-ante uncertain (is might depend on a technological breakthrough). It might turn out to be high, $c_{0}(x)$, or low, $c_{1}(x)$, with $c_{0}^{\prime}(x)>c_{1}^{\prime}(x)$ for all precaution levels $x \geq 0$. The probability of harm is $p(x)$, with $p^{\prime}(x)<0$. Since the victims are risk averse, the cost of harm for each of them is not $p(x) h$, but: $\ell(x)>p(x) h$. In fact, $\ell(x)$ is the amount that each victim would be willing to pay to get full insurance against harm (it includes a risk premium).

The policy maker decides which precautionary measures should be taken (a standard of care), once the uncertainty about precaution costs has unfolded. Suppose that the marginal cost of precaution turns out to be high. The standard $x_{0}^{c}$ prescribed by conventional cost-benefit analysis is the one that equates marginal cost and marginal benefits (the reduction in the cost of harm for the victims): $c^{\prime}\left(x_{0}^{c}\right)=-n \ell^{\prime}\left(x_{0}^{c}\right)$. One dollar invested in precaution should reduce the cost of harm for the victims by one dollar. Figure 1 illustrates. 


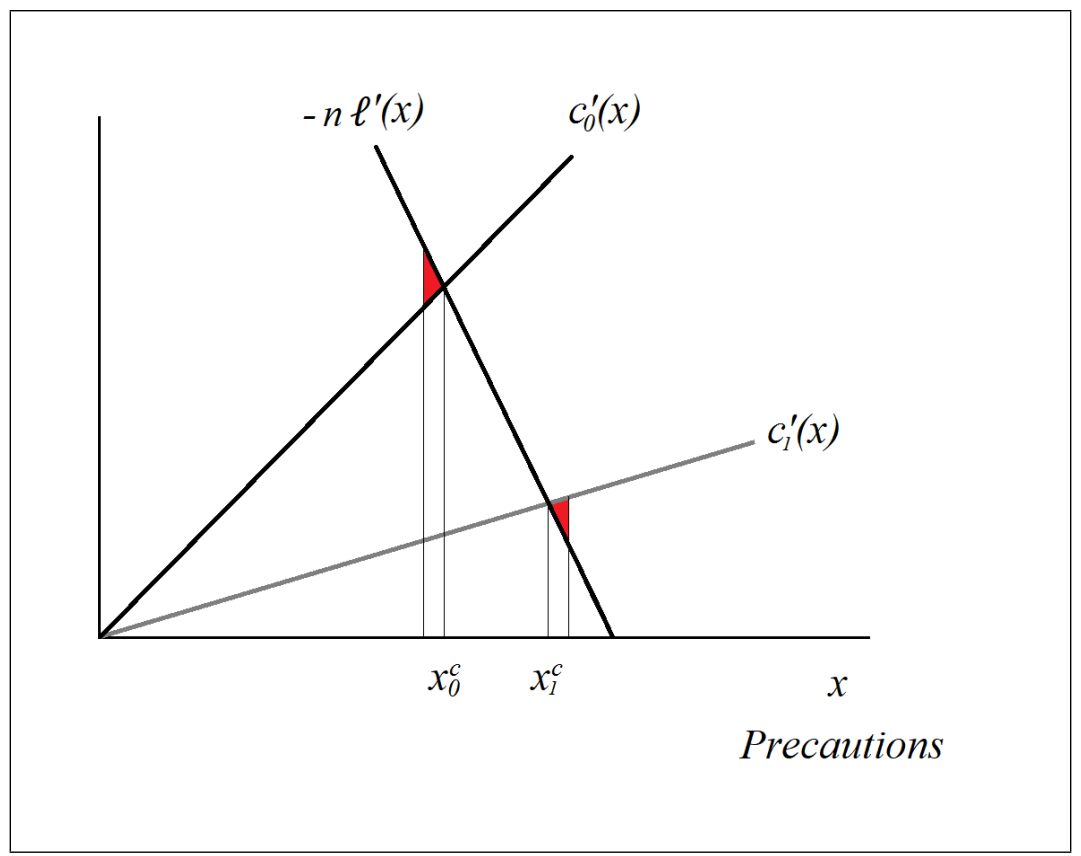

Fig. 1. Optimal attenuation.

If the marginal cost of precaution turns out to low, the standard suggested by costbenefit analysis is $x_{1}^{c}$. Note that, ex-ante, before the cost of precaution is known, both the injurer and the victims are subject to uncertainty. The injurer does not know whether she will bear cost $c_{0}\left(x_{0}^{c}\right)$ or $c_{1}\left(x_{1}^{c}\right)$. The victims do not know whether they will face cost of harm $n \ell\left(x_{0}^{c}\right)$ or $n \ell\left(x_{1}^{c}\right)$, with $n \ell\left(x_{0}^{c}\right)>n \ell\left(x_{1}^{c}\right)$ (to fix ideas).

Let us consider the effect of a variation in $x_{0}^{c}$. By reducing the standard $x_{0}^{c}$, the policy maker invites the injurer to forgo precautionary measures that are more beneficial than costly. However, the resulting distortion - the small shaded triangle - is negligible. What is substantial, instead, is the impact on the size of the risk borne by the parties: the ex-ante uncertainty faced by the injurer decreases (since the wedge between $c_{0}\left(x_{0}\right)$ and $c_{1}\left(x_{1}\right)$ decreases), while, symmetrically, the ex-ante uncertainty faced by the victims increases. The net effect is not null, because parties are likely to have a different capacity to bear additional risk (because they might have different attitudes towards risk and because the size of the risk they already bear is different - in general, the higher the risk already borne, the more costly the addition of risk). So, if the injurer is less able to bear additional risk, the standard should decrease, and the other way around if the 
victims are less able to bear additional risk.

On the basis of similar considerations, the standard $x_{1}$ should also be be modified. Here, however, the direction of the change is the opposite of the previous one: $x_{1}$ should decrease if, and only if, the injurer is better able to bear additional risk.

A second order approximation, in which $\alpha_{I}$ and $\alpha_{V}$ are, respectively, the degrees of risk aversion of injurer and victims, yields this simple rule:

\section{Optimal attenuation}

If $\alpha_{I}\left[c_{0}\left(x_{0}^{c}\right)-c_{1}\left(x_{1}^{c}\right)\right]>\alpha_{V}\left[\ell\left(x_{0}^{c}\right)-\ell\left(x_{1}^{c}\right)\right], x_{0}^{c}$ should be decreased and $x_{1}^{c}$ increased.

If $\alpha_{I}\left[c_{0}\left(x_{0}^{c}\right)-c_{1}\left(x_{1}^{c}\right)\right]<\alpha_{V}\left[\ell\left(x_{0}^{c}\right)-\ell\left(x_{1}^{c}\right)\right], x_{0}^{c}$ should be increased and $x_{1}^{c}$ decreased.

Note that this rule is unaffected by the numerosity of the victims (numerosity affects instead the level of the conventional standards).

The precise amount by which $x_{0}^{c}$ and $x_{1}^{c}$ should change depends on the degree of risk aversion of the parties and the size of the risk they bear. Additionally, if the marginal cost and marginal harm curves are highly elastic (marginal costs and marginal harm are nearly constant), the cost of distorting the conventional policy is smaller, and the optimal distortion is larger.

More generally, when both harm and costs are uncertain, the direction of the distortion will depend on whether parties are subject to positive or negative shocks. For example, if costs turn out to be high and the probability of harm low, a reduction in the standard is beneficial to both the injurer and the victims.

- Illustration. Let us consider the case in which it is discovered that some common food has been heavily contaminated (the probability of harm jumps upwards). The public authority imposes specific containment measures on the industry operators such as destruction of inventories, removal from shelves, extra monitoring - to reduce the risk to the public. Such measures represent a cost for those operators but offer some reassurance to the population. Suppose that operators are mostly large companies indifferent to risk. Here, an efficient safety policy requires that containment measures are intensified beyond the level that ordinary cost-benefit analysis suggests. ${ }^{14}$

\footnotetext{
${ }^{14}$ If firms and consumers were tied by a contractual relationship, such additional containment mea-
} 


\section{Regulation of behavior}

Let us consider the case in which both the costs and the probability of harm associated with a certain activity are uncertain. They will only be known at a future date. At that date, when uncertainty has unravelled, a suitable standard of behavior will be applied. The standard will be enforced either through pecuniary and criminal sanctions, or simple negligence law.

With probability $q$, the cost of taking precautions is $c_{0}(x)$ and the probability that victims suffer harm is $p_{0}(x)$, with $c_{0}^{\prime}(x)>0$ for $x>0, c_{0}^{\prime}(0)=0, \lim _{x_{0} \rightarrow \infty} c_{0}^{\prime}(x)=\infty$, $c_{0}^{\prime \prime}(x) \geq 0, p_{0}^{\prime}(x)<0$, and $p_{0}^{\prime \prime}(x) \geq 0$.

With probability $1-q$, the cost of taking precautions is $c_{1}(x)$ and the probability that victims suffer harm is $p_{1}(x)$, where $c_{1}(x)$ and $p_{1}(x)$ meet the regularity conditions listed above.

The magnitude of harm is fixed and equal to $h$ for each victim. ${ }^{15}$ There are $n_{V}$ identical victims and $n_{I}$ identical injurers. The policy maker sets the standards $x_{0}$ and $x_{1}$ before uncertainty has been resolved and commits not to change them. ${ }^{16}$ So, the time line unfolds as follows: i) the policymaker decides how to fix the standards, ii) uncertainty about costs and benefits of precaution unravels, iii) the standards are enforced and with some probability victims suffer harm.

Agents maximize their expected utility and the policymaker pursues Pareto efficiency (in other words, the policymaker maximizes the expected utility that agents can get from this situation). In line with this article's introductory observations, I assume that insurance is not available. So, injurers are subject to the risk associated with the variability of precaution costs, while victims are subject to the risk of harm, with a probability that is itself ex-ante uncertain.

sures would be part of the efficient contract.

${ }^{15}$ Results can be easily extended to the case in which also victims invest in precautions (bilateral accidents), precautions affect the magnitude of harm (instead of its probability), and ex-ante uncertainty does not take a binary shape.

${ }^{16}$ This assumption presumes that the policymaker adopts a decision rule that accounts for the contingency under which decisions are made (positive or negative shocks affecting the parties). In the author's view, this feature is in line with actual policy making: the introduction of costly regulations is often delayed when industries are experiencing a downturn. 
We can now turn to the optimal policy. As noted in the introduction, the policy maker will find it optimal to deviate from the prescriptions of conventional cost-benefit analysis. In order to see in which direction policy changes, let us first analyze the "conventional" standards, that is the standards that are optimal ex-post, when uncertainty has unravelled. ${ }^{17}$

Let us suppose that state 0 has occurred. Let us consider the payoff of the victims. Given the level of precaution taken by the injurers, the expected utility of each victim is

$$
\widehat{E U}_{0}^{V}\left(x_{0}\right)=\left(1-p_{0}\left(x_{0}\right)\right) v\left(y_{V}\right)+p_{0}\left(x_{0}\right) v\left(y_{V}-h\right)
$$

where $v(y)$ is the victim's utility function, with $v^{\prime}(y)>0$ and $v^{\prime \prime}(y) \leq 0$, and $y_{V}$ is his income level.

For the sake of the analysis, let us calculate the certainty equivalent of $\widehat{E U}_{0}^{V}\left(x_{0}\right)$, i.e., the amount $y_{V}-\ell_{0}\left(x_{0}\right)$ such that

$$
v\left(y_{V}-\ell_{0}\left(x_{0}\right)\right)=\widehat{E U}_{0}^{V}\left(x_{0}\right) .
$$

$\ell_{0}\left(x_{0}\right)$ is amount that each victim is willing to pay to get full insurance against harm. It represents the "cost of harm" for the victim. The cost of harm can be divided in two components: the expected loss $p_{0}\left(x_{0}\right) h$ and a residual part, called risk premium, which accounts for the loss due to the uncertainty about the occurrence of harm:

$$
\ell_{0}\left(x_{0}\right)=p_{0}\left(x_{0}\right) h+R P_{0}^{V}\left(x_{0}\right)
$$

Note that the risk premium is larger if the agent is more averse to risk (i.e., if $v$ is subject to a concave monotone transformation). One can easily see that if the standard of care $x_{0}$ increases, the probability of harm decreases and the cost of harm $\ell_{0}\left(x_{0}\right)$ decreases. If $h$ increases, $\ell_{0}\left(x_{0}\right)$ increases.

We can now turn to the optimal determination of the standard in the conventional

\footnotetext{
${ }^{17}$ Shavell $(2014 \mathrm{~b})$ uses the same definition. However, since in his model victims can buy insurance once uncertainty has unravelled, his conventional standards coincide with the standards that would emerge if all parties were risk neutral.
} 
case. In Appendix A1, I show that the (ex-post) optimal policy can be obtained by maximizing the sum the certainty equivalents of the affected parties. This procedure is fully equivalent to the tradition approach, based on the maximization of expected utilities. Ex-post social welfare is therefore:

$$
\widehat{W}_{0}\left(x_{0}\right)=n_{I}\left[y_{I}-c_{0}\left(x_{0}\right)\right]+n_{V}\left[y_{V}-\ell_{0}\left(x_{0}\right)\right]
$$

where $y_{I}$ is the income of each injurer. Note that here injurers are subject to no uncertainty (they have to pay $c_{0}\left(x_{0}\right)$ for sure).

The optimal conventional standard $x_{0}^{c}$ must satisfy $\widehat{W}_{0}^{\prime}\left(x_{0}^{c}\right)=0$, and thus:

$$
n_{I} c_{0}^{\prime}\left(x_{0}^{c}\right)=-n_{V} \ell_{0}^{\prime}\left(x_{0}^{c}\right)
$$

Eq. (3) is a classic application of cost-benefit analysis to risk prevention: an additional dollar spent in prevention should reduce the cost of harm for the victims by one dollar. ${ }^{18}$

Note that the conventional standard $x_{0}^{c}$ increases if $n_{V}$ increases or $n_{I}$ decreases: social marginal costs increase if the number of injurers is larger, social marginal benefits increase if the number of potential victims is larger.

Similarly, the optimal conventional standard in state $1, x_{1}^{c}$, must satisfy $\widehat{W}_{1}^{\prime}\left(x_{1}^{c}\right)=0$, and thus:

$$
n_{I} c_{1}^{\prime}\left(x_{1}^{c}\right)=-n_{V} \ell_{1}^{\prime}\left(x_{1}^{c}\right)
$$

Note that $x_{1}^{c}$ might be larger or smaller than $x_{0}^{c}$.

Let us consider now the optimal standards from an ex-ante perspective, before uncertainty about costs and benefits of precaution has unravelled. By going through steps similar to those above (see Appendix A1), we get that the ex-ante cost of precaution for the injurers (i.e., the amount that they would be willing to spend to get full insurance

\footnotetext{
${ }^{18}$ In general, we do not know if risk aversion calls for a higher or lower standard, since $R P_{0}^{V}\left(x_{0}\right)$ can increase or decrease with the probability of harm - see Shavell (1982). Risk aversion calls for a higher standard if the probability of harm is "sufficiently small" (e.g., if it is less than $1 / 2$ under quadratic utility). See Jullien et al. (1999).
} 
against precaution costs) is

$$
\ell_{I}^{\text {ex-ante }}\left(x_{0}, x_{1}\right)=q c_{0}\left(x_{0}\right)+(1-q) c_{1}\left(x_{1}\right)+R_{I} .
$$

The ex-ante cost of precaution includes the expected costs plus a risk premium $R_{I}$ due to ex-ante uncertainty. $R_{I}$ goes up if the wedge between $c_{0}\left(x_{0}\right)$ and $c_{1}\left(x_{1}\right)$ increases, and if the injurer is more averse to risk. ${ }^{19}$

The ex-ante cost of harm for the victims can be written as:

$$
\ell_{V}^{e x-\text { ante }}\left(x_{0}, x_{1}\right)=q \ell_{0}\left(x_{0}\right)+(1-q) \ell_{1}\left(x_{1}\right)+R_{V}
$$

The ex-ante cost of harm includes the expected cost of harm and a risk premium due to the ex-ante uncertainty about the probability of harm. $R_{V}$ increases if the wedge between $\ell_{0}\left(x_{0}\right)$ and $\ell_{1}\left(x_{1}\right)$ increases, and if the victims are more averse to risk (given $\ell_{1}$ and $\ell_{0}, R_{V}$ increases if $v$ is subject to a concave monotone transformation).

We are now ready to calculate the ex-ante optimal policy. The optimal standards should maximize ex-ante social welfare (again based on certainty equivalents):

$$
\begin{aligned}
& W^{e x-a n t e}\left(x_{0}, x_{1}\right)=n_{I}\left[y_{I}-\ell_{I}^{e x-a n t e}\left(x_{0}, x_{1}\right)\right]+n_{V}\left[y_{V}-\ell_{V}^{e x-a n t e}\left(x_{0}, x_{1}\right)\right] \\
& =q\left[n_{I}\left(y_{I}-c_{0}\left(x_{0}\right)\right)-n_{V}\left(y_{0}-\ell_{0}\left(x_{0}\right)\right)\right] \\
& \quad+(1-q)\left[n_{I}\left(y_{I}-c_{1}\left(x_{1}\right)\right)-n_{V}\left(y_{I}-\ell_{1}\left(x_{1}\right)\right)\right]-n_{I} R_{I}-n_{V} R_{V} .
\end{aligned}
$$

Thus,

$$
W^{\text {ex-ante }}\left(x_{0}, x_{1}\right)=q \widehat{W}_{0}\left(x_{0}\right)+(1-q) \widehat{W}_{1}\left(x_{1}\right)-n_{I} R_{I}-n_{V} R_{V}
$$

Ex-ante social welfare is equal to the expected ex-post social welfare minus the risk premiums of injurers and victims due to ex-ante uncertainty. Equation (6) shows that the ex-ante optimal policy must differ from the ex-post optimal policy, since the latter does

\footnotetext{
${ }^{19}$ Note that also firms tend to display risk aversion (and purchase insurance, when available). Several explanations for this fact have been provided, including the cost of bankruptcy (which leads firms to avoid very adverse outcomes), the cost of external funds (which might be needed in adverse states), asymmetric information (the firm's behavior reflects the risk aversion of directors and managers whose remuneration depends on the firm's performance), a convex tax schedule, and debt overhang (the underinvestment caused by debt can be reduced if risks are managed).
} 
not account for the cost of ex-ante uncertainty. In deciding the optimal standards, the policy maker should balance the impact on ex-post social welfare (i.e. the deadweight loss of the distortion), the impact on the uncertainty burden of the injurers, and the impact on the uncertainty burden of the victims.

The following result tells us in which direction conventional standards should be modified.

\section{Proposition 1 Regulation of behavior.}

a) The standard $x_{0}^{c}$ should be increased if, and only if, $\frac{\partial R_{I}}{\partial c_{0}\left(x_{0}^{c}\right)}<\frac{\partial R_{V}}{\partial \ell_{0}\left(x_{0}^{c}\right)}$.

b) The standard $x_{1}^{c}$ should be increased if, and only if, $\frac{\partial R_{I}}{\partial c_{1}\left(x_{1}^{c}\right)}<\frac{\partial R_{V}}{\partial \ell_{1}\left(x_{1}^{c}\right)}$.

Proof. See Appendix A1.

The optimal attenuation policy requires that the conventional standards be modified to mitigate the ex-ante uncertainty borne by injurers and victims. The expression guiding the direction of change is very simple, since it depends on whether the impact of a one-dollar increase in the cost of precaution on the uncertainty burden of an injurer is greater or less than the impact of a one-dollar increase in the cost of harm on the uncertainty burden of a victim.

Note that the inequalities of Proposition 1 can be easily verified if injurers and victims are subject to shocks of opposite sign. Let us focus on $x_{0}$. If injurers are subject to a positive shock $\left(c_{0}\left(x_{0}^{c}\right)<c_{1}\left(x_{1}^{c}\right)\right)$ and victims are subject to a negative shock $\left(\ell_{0}\left(x_{0}^{c}\right)>\ell_{1}\left(x_{1}^{c}\right)\right)$, then $\frac{\partial R_{I}}{\partial c_{0}\left(x_{0}^{c}\right)}<0$ and $\frac{\partial R_{V}}{\partial \ell_{0}\left(x_{0}^{c}\right)}>0$ : an increase in the conventional standard $x_{0}^{c}$ reduces the ex-ante risk premiums of both injurers and victims.

The direction of change cannot be determined in an obvious manner when injurers and victims are subject to shocks of the same sign. In such situations, the direction of change will depend on which party is in an a better position to bear additional (ex-ante) risk. This will in general depend on: i) the size of the shock (that is $\left|c_{0}\left(x_{0}^{c}\right)-c_{1}\left(x_{1}^{c}\right)\right|$ and $\left.\left|\ell_{0}\left(x_{0}^{c}\right)-\ell_{1}\left(x_{1}^{c}\right)\right|\right)$, ii) the parties' disposition towards risk.

Note that what determines the direction of change is not the aggregate size of the risk, but the individual size (the impact of an increase in aggregate risk depends on how much risk each agent is already bearing). 
Proposition 1 determines the optimal direction of change with respect to the conventional standards. The precise magnitude by which they should be modified depends on the degree of risk aversion of the parties and the size of the risk they bear. Additionally, if the marginal cost and the marginal benefit curves are highly inelastic (marginal costs and marginal benefits are nearly constant), the cost of distorting the conventional policy is smaller, and the optimal modification is larger.

\section{Liability for harm}

Let us now consider the case in which injurers are liable for the harm caused. The policy maker decides the level of damages to be paid to each victim ( $d_{0}$ if state 0 occurs, $d_{1}$ if state 1 occurs). Each injurer faces $n=n_{V} / n_{I}$ victims. Damages are independent of the level of care taken (i.e., strict liability applies), and liability is clearly assigned to the responsible injurer. Damages can undercompensate (e.g., pain and suffering are not included, or caps are imposed) or overcompensate (they are generously calculated or they include punitive elements). Each victim suffers harm $h$ with probability either $p_{0}(x)$ or $p_{1}(x)$.

Let us start again with the conventional levels of damages, i.e. the damages that would be optimal ex-post, when uncertainty about the precaution costs and the probability of harm has unfolded. Let us focus on state 0 . The cost of harm $\ell_{0}^{I}\left(x_{0}\right)$ for the injurer is

$$
\ell_{0}^{I}\left(x_{0}\right)=c_{0}\left(x_{0}\right)+p_{0}\left(x_{0}\right) n d_{0}+R P_{0}^{I}\left(n d_{0}\right),
$$

where $R P_{0}^{I}\left(n d_{0}\right)$ is the risk premium attendant with the risk of bearing liability $n d_{0}$ with probability $p_{0}\left(x_{0}\right){ }^{20}$

The level of precaution $x_{0}^{I}$ is decided by the injurer to minimize her cost of harm (precautions are costly but reduce prospective liability).

The cost of harm for each victim is:

$$
\ell_{0}^{V}\left(x_{0}^{I}\right)=p_{0}\left(x_{0}^{I}\right)\left(h-d_{0}\right)+R P_{0}^{V}\left(h-d_{0}\right),
$$

\footnotetext{
${ }^{20}$ Harms are assumed to be perfectly correlated. Optimal liability law with imperfectly correlated harms is studied in Franzoni (2016). Correlation affects the size of the risk premium.
} 
where $R P_{0}^{V}\left(h-d_{0}\right)$ is the risk premium attendant with the prospect of bearing uncompensated harm $h-d_{0}$ with probability $p_{0}\left(x_{0}^{I}\right)$. The victim's cost of harm increases with $h-d_{0}$ and with $p_{0}\left(x_{0}^{I}\right)$.

The optimal conventional policy can be found by maximizing ex-post social welfare (per injurer):

$$
W_{0}^{S L}\left(d_{0}\right)=y_{I}-\ell_{0}^{I}\left(x_{0}^{I}\right)+n\left[y_{V}-\ell_{0}^{V}\left(x_{0}^{I}\right)\right] .
$$

Thus, conventional damages $d_{0}^{c}$ solve:

$$
\frac{W_{0}^{S L}\left(d_{0}^{c}\right)}{\partial d_{0}}=-\frac{\partial \ell_{0}^{I}\left(x_{0}^{I}\right)}{\partial d_{0}}-n \frac{\partial \ell_{0}^{V}\left(x_{0}^{I}\right)}{\partial d_{0}}=0 .
$$

Note that damages affect both the level of precaution taken by the injurer and the allocation of risk between the parties (see Appendix A2).

With risk averse victims, optimal (conventional) damages are under-compensatory: $d_{0}^{c}<h$ (as first proved by Shavell (1982)). The intuition is the following: when damages are compensatory $\left(d_{0}^{c}=h\right)$, the injurer fully internalizes the negative impact she exerts on the victims, so incentives to take precautions are properly set. The allocation of risk, however, is not optimal, because all the risk is borne by the injurer. The allocation of risk can be improved at the margin, with a negligible effect on incentives, by reducing the level of damages and by shifting a small amount of the loss on the victims. The impact on the risk burden of the victims is negligible (for small losses, people behave as if they were risk neutral), while the impact on the risk burden of the injurer is substantial. ${ }^{21}$

Similar definitions and results apply to state 1.

Let us consider the optimal policy before uncertainty unravels. The ex-ante cost of harm for injurer and victims are, respectively,

$$
\begin{aligned}
& \ell_{I}^{e x-\text { ante }}\left(d_{0}, d_{1}\right)=q \ell_{0}^{I}\left(x_{0}^{I}\right)+(1-q) \ell_{1}^{I}\left(x_{1}^{I}\right)+R_{I}, \\
& \ell_{V}^{\text {ex-ante }}\left(d_{0}, d_{1}\right)=q \ell_{0}^{V}\left(x_{0}^{I}\right)+(1-q) \ell_{1}^{V}\left(x_{1}^{I}\right)+R_{V}
\end{aligned}
$$

${ }^{21}$ This result breaks down if victims display first-order risk aversion (see Franzoni (2017)). 
where $R_{I}$ and $R_{V}$ are the risk premiums due to the ex-ante uncertainty.

Ex-ante social welfare can be written, therefore, as

$$
\begin{aligned}
W^{\text {ex-ante }}\left(d_{0}, d_{1}\right) & =\ell_{I}^{\text {ex-ante }}\left(d_{0}, d_{1}\right)+n \ell_{V}^{\text {ex-ante }}\left(d_{0}, d_{1}\right) \\
& =q W_{0}^{S L}\left(d_{0}\right)+(1-q) W_{1}^{S L}\left(d_{1}\right)-R_{I}-n R_{V}
\end{aligned}
$$

As in the previous section, ex-ante social welfare differs from ex-post social welfare. The ex-ante optimal policy must account for the cost of uncertainty. The following result applies.

\section{Proposition 2 Liability for harm caused.}

a) Damages $d_{0}^{c}$ should be increased if, and only if, $\frac{\partial R_{I}}{\partial \ell_{0}^{I}\left(x_{0}^{I}\right)}<\frac{\partial R_{V}}{\partial \ell_{0}^{V}\left(x_{0}^{V}\right)}$;

b) Damages $d_{1}^{c}$ should be increased if, and only if, $\frac{\partial R_{I}}{\partial \ell_{0}^{I}\left(x_{0}^{I}\right)}<\frac{\partial R_{V}}{\partial \ell_{0}^{V}\left(x_{0}^{V}\right)}$.

Proof. See Appendix A2.

Proposition 2 mimics Proposition 1. Optimal attenuation requires a modification of the ex-post optimal policy. Damages should be increased if injurers are subject to a positive shock while victims are subject to a negative shock (and the other way around).

When parties are subject to shocks with the same sign, attenuation should take care of the party that benefits most from a reduction in ex-ante risk. ${ }^{22}$

In Appendix A2, I show that optimal damages may be overcompensatory: $d_{0}^{*}>h$ ( or $d_{1}^{*}>h$ ). Under risk neutrality, optimal damages are perfectly compensatory. Under risk aversion, a deviation from the risk-neutral benchmark is desirable, for a better allocation of risk. In the neighborhood of $d_{0}^{*}=d_{1}^{*}=h$, a small change in damages has no effect on the victims, who are fully insured against harm. So, the relevant impact is on the risk burden of the injurer. If ex-post risk is what matters most, damages should be reduced (both $d_{0}^{*}$ and $d_{1}^{*}$ ). If ex-ante risk is what matters most - because ex-ante

\footnotetext{
${ }^{22}$ In most cases, injurers are likely to bear greater ex-ante uncertainty than victims. For the injurers, ex-ante uncertainty stems from the variability of precaution costs and liability expenses. For the victims, ex-ante uncertainty stems from the variability of expected uncompensated harm. So, if damages are not too far from the harm suffered, attenuation is likely to be geared towards the injurers.
} 
uncertainty is substantial - damages should be overcompensatory in the presence of a positive shock, and under-compensatory in the presence of a negative shock.

\section{Corrective taxation}

Let us now suppose that the government relies on corrective taxation to encourage precaution (or, equivalently, a reduction in emissions). I focus on simple linear taxes:

$$
T_{0}\left(x_{0}\right)=t_{0}\left(X-x_{0}\right), \text { and } T_{1}\left(x_{1}\right)=t_{1}\left(X-x_{1}\right) .
$$

$X$ captures the "baseline" level of precaution. If the injurer does less than $X$, she pays a tax; if she does more, she gets a subsidy. In the case of an emission tax, $X$ represents the fixed emissions allowance. So, this mechanism also captures a cap-and-trade policy. ${ }^{23}$

$X$ is assumed to be fixed. If $X$ could vary across states, it could be used to provide perfect insurance to the injurers (with a large $X$ in bad states, and a small $X$ in good states). If that were the case, the only remaining concern for the policy maker would be to provide insurance to the victims. In the present model, the latter case can be captured by assuming that injurers are risk neutral.

Let us focus on state 0 . The ex-post payoff of the injurer is $y_{I}-\ell_{0}^{I}\left(x_{0}\right)$, where the cost of harm for the injurer is

$$
\ell_{0}^{I}\left(x_{0}\right)=c_{0}\left(x_{0}\right)+t_{0}\left(X-x_{0}\right)
$$

The cost of harm includes precaution costs and the tax payment (or subsidy).

The injurer selects the level of precaution $x_{0}^{I}$ that minimizes her cost of harm, with

$$
c_{0}^{\prime}\left(x_{0}^{I}\right)=t_{0}
$$

\footnotetext{
${ }^{23}$ Shavell $(2014 \mathrm{~b})$ considers the case in which the tax depends on the probability of harm, $T_{0}(x)=$ $t_{0} p_{0}(x)$, and victims are risk-neutral. The optimal conventional level of $t_{0}$ is $h$, so that $T_{0}^{\prime}(x)=p_{0}^{\prime}(x) h$. This formulation mimics the liability for harm case (with injurers insured against liability). Non-linear taxes are theoretically superior (see Kaplow and Shavell (2002)), but they entail large administrative costs. The current policy debate focuses on linear taxes and cap-and-trade (possibly with a collar).
} 
The injurer takes precautions to avoid the tax (or increase the subsidy). We have

$$
\frac{\partial \ell_{0}^{I}\left(x_{0}^{I}\right)}{\partial t_{0}}=\frac{\partial \ell_{0}^{I}\left(x_{0}^{I}\right)}{\partial x_{0}^{I}} \frac{\partial x_{0}^{I}}{\partial t_{0}}+\left.\frac{\partial \ell_{0}^{I}\left(x_{0}^{I}\right)}{\partial t_{0}}\right|_{x_{0}=x_{0}^{I}}=X-x_{0}
$$

since $\frac{\partial \ell_{0}^{I}\left(x_{0}^{I}\right)}{\partial x_{0}^{I}}=0$. An increase in the tax rate induces the injurer to take additional precautions, whose costs and benefits are perfectly balanced. So, the increase in the tax impacts the payoff of the injurer only by means of the additional tax outlays, which are positive in the case of a $\operatorname{tax}$ (if $X>x_{0}$ ) and negative in the case of a subsidy (if $\left.X<x_{0}\right)$.

The ex-post cost of harm for a victim is:

$$
\ell_{0}^{V}\left(x_{0}^{I}\right)=p_{0}\left(x_{0}^{I}\right) h+R P_{0}^{V}\left(x_{0}^{I}\right),
$$

where $p_{0}\left(x_{0}^{I}\right) h$ is the expected harm and $R P_{0}^{V}\left(x_{0}^{I}\right)$ the risk premium attendant with the harm prospect. If the tax rate $t_{0}$ increases, injurers take additional precautions, and the victims's cost of harm decreases.

Ex-post social welfare is equal to the injurer's payoff plus the victims payoff plus the tax revenue (that can be redistributed to society at large): ${ }^{24}$

$$
\begin{aligned}
\widehat{W}_{0}\left(t_{0}\right) & =y_{I}-\ell_{0}^{I}\left(x_{0}^{I}\right)+n\left[y_{V}-\ell_{0}^{V}\left(x_{0}^{I}\right)\right]+T_{0}\left(x_{0}\right) \\
& =y_{I}-c_{0}\left(x_{0}^{I}\right)-T_{0}\left(x_{0}\right)+n\left[y_{V}-\ell_{0}^{V}\left(x_{0}^{I}\right)\right]+T_{0}\left(x_{0}\right) \\
& =y_{I}-c_{0}\left(x_{0}^{I}\right)+n\left[y_{V}-\ell_{0}^{V}\left(x_{0}^{I}\right)\right] .
\end{aligned}
$$

Note that the tax only affects social welfare indirectly, by means of its impact on the

\footnotetext{
${ }^{24}$ I assume that the tax revenue is distributed to all members of society (thus, the impact on individual incomes is negligible). If the tax revenue were distributed to the victims only, the corrective taxation regime would resemble the liability regime, except for the fact that the tax is levied on all injurers and not only on those who happen to cause an accident. So, the tax would provide liability insurance to the injurers. The tax revenue could alternatively be returned (in a lump-sum fashion) only to the injurers. In the present model, such an outcome can be mimicked by suitably changing the benchmark $X$ (so as to bring the net payment of each injurer to zero). This solution would eliminate the ex-ante uncertainty on the injurers' side.
} 
precaution level $x_{0}^{I}$.

The optimal conventional tax rate solves:

$$
\frac{\partial \widehat{W}_{0}\left(t_{0}\right)}{\partial t_{0}}=\frac{\partial x_{0}^{I}}{\partial t_{0}}\left[c_{0}^{\prime}\left(x_{0}^{I}\right)+n \ell_{0}^{V \prime}\left(x_{0}^{I}\right)\right]=0 .
$$

At the ex-post optimum, marginal costs equate marginal benefits of precaution. Using (9), we get: $t_{0}^{c}=c_{0}^{\prime}\left(x_{0}^{I}\right)=-n \ell_{0}^{V \prime}\left(x_{0}^{I}\right)$. Note that if the number of victims increases, the marginal benefit of precaution increases and $t_{0}^{c}$ increases.

In state 1 , by similarity, we have : $t_{1}^{c}=c_{1}^{\prime}\left(x_{1}^{I}\right)=-n \ell_{1}^{V^{\prime}}\left(x_{1}^{I}\right)$ (see Figure 2 below).

Let us move to the ex-ante stage. Ex-ante social welfare can be written, going through the usual steps, as

$$
W^{\text {ex-ante }}\left(t_{0}, t_{1}\right)=q \widehat{W}_{0}\left(t_{0}\right)+(1-q) \widehat{W}_{1}\left(t_{1}\right)-R_{I}-n R_{V}
$$

where $R_{I}$ and $R_{V}$ are the ex-ante risk premiums of injurer and victims, respectively, due to ex-ante uncertainty. Again, a change in policy affects both ex-post welfare and the ex-ante risk burden of the parties.

In order to establish in which direction conventional policy should be changed, one should compare the impact of a change in the tax rate on the risk burdens of injurers and victims. In contrast to the cases analyzed in the previous sections, here a policy change impacts the (ex-post) payoffs of the parties in a non-symmetric way. Fig. 2 illustrates. 


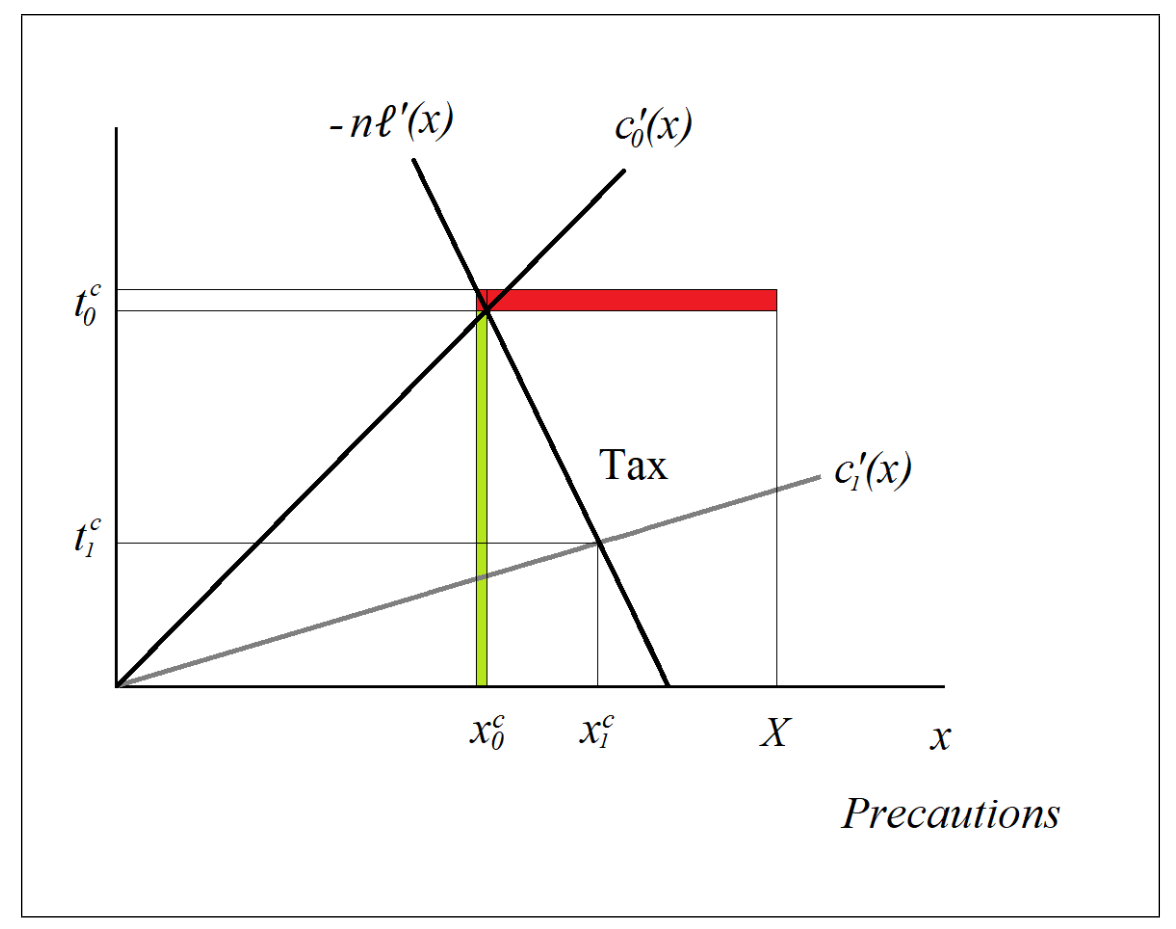

Fig. 2. Corrective taxation.

An increase in the tax affects the tax outlays of the injurer by the amount $X-x_{0}^{c}$ - the horizontal shaded area (in this case, the amount $X-x_{0}^{c}$ is a loss because $X>x_{0}^{c}$ ). At the same time, it increases the cost of harm for the victims by an amount that depends on the sensitivity of precautions to the tax - the vertical shaded area. If marginal precaution costs are very steep, a reduction in the tax has a small effect on the victims. Thus, on the victims' side, what matters is the elasticity of precautions with respect to the tax rate,

$$
\varepsilon_{t_{0}}^{x_{0}}=\frac{\partial x_{0}^{I}}{\partial t_{0}} \frac{t_{0}^{c}}{x_{0}^{I}}=\frac{1}{c_{0}^{\prime \prime}\left(x_{0}^{I}\right)} \frac{t_{0}^{c}}{x_{0}^{I}}>0,
$$

(from 9). The following Proposition identifies the direction in which the ex-post optimal policy should be changed.

\section{Proposition 3 Corrective taxation.}

a) The tax $t_{0}^{c}$ should be increased if, and only if, $\frac{\partial R_{I}}{\partial \ell_{0}^{I}\left(x_{0}^{I}\right)} \frac{X-x_{0}^{I}}{x_{0}^{I}}<\frac{\partial R_{V}}{\partial \ell_{0}^{V}\left(x_{0}^{I}\right)} \varepsilon_{t_{0}}^{x_{0}}$;

b) The tax $t_{1}^{c}$ should be increased if, and only if, $\frac{\partial R_{I}}{\partial \ell_{1}^{I}\left(x_{1}^{I}\right)} \frac{X-x_{1}^{I}}{x_{1}^{I}}<\frac{\partial R_{V}}{\partial \ell_{1}^{V}\left(x_{1}^{I}\right)} \varepsilon_{t_{1}}^{x_{1}}$. 
Proof. See Appendix A3.

The inequalities of Proposition 3 are substantially different from those obtained in the previous sections. The direction of change of the conventional policy depends, in addition to the sign of the shocks (positive or negative), on the impact of an increase in the tax rate on the outlays of the injurer and on the elasticity of precaution. ${ }^{25}$ If precautions are relatively inelastic (marginal costs are steep), policy should only focus on mitigating the risk borne by the injurers (and vice versa).

If the injurer is risk averse and the victims are risk neutral, the tax outlays should be decreased under a negative shock for the injurer, while they should be increased under a positive shock. ${ }^{26}$ The decrease in the tax outlays is obtained by a decrease in $t_{0}^{c}$ if $X>x_{0}^{I}$ (tax) and the other way around if $X<x_{0}^{I}$ (subsidy).

If the injurer is risk neutral and victims are risk averse, the tax rate should be increased under a negative shock for the victims, while it should be decreased under a positive shock. This case also captures the situation in which the baseline level of precaution $X$ can be adjusted according to the circumstances.

\section{Extensions}

- Choice of instrument. The analysis of the previous sections focuses on the optimal attenuation given the policy instrument. Note that all instruments are equally efficient when injurers and victims are risk neutral. They differ substantially, instead, when parties are risk averse.

Under regulatory standards, injurers face uncertainty about precaution costs, while victims bear the risk of harm. Under liability, injurers face uncertainty about precaution costs and liability exposure, while victims bear the risk of being undercompensated. Under taxes, injurers face uncertainty about precaution costs and tax payments (if

\footnotetext{
${ }^{25}$ Under a cap-and-trade system, a change in the tax is equivalent to a change in the price of the emission permits.

${ }^{26}$ This case offers a rationale for the "cost containment" policies advanced in environmental policy (safety valves, collars, etc.). See Aldy (2017).
} 
$X$ is fixed). Victims bear the risk of harm. These three allocations cannot be easily compared, except for some special cases.

If injurers are risk neutral and victims risk averse, strict liability with full compensation yields the first best. Injurers bear all the risk, while victims are perfectly insured.

If victims are risk neutral and injurers are risk averse, regulation and taxation are likely to fare better. ${ }^{27}$ Under corrective taxation, if the allowance $X$ is suitably adjusted, injurers can be fully insured. So, corrective taxation dominates all other instruments.

- Ambiguity aversion. The results of this article show that the optimal policy should reduce the ex-ante uncertainty for the parties, even when this uncertainty is about the probability of harm. Thus, parties should be treated as if they were averse to compound lotteries, even if they are not (in line with expected utility theory).

There is ample empirical evidence that individuals do not always behave in line with expected utility theory. In particular, if the probabilities with which they deal do have a "subjective" nature, rather than an "objective" one, then aversion to compound lotteries tends to arise (this is technically called "ambiguity aversion"). ${ }^{28}$ In Appendix A5, I show that if victims are averse to ambiguity (in the sense of Klibanoff et al. (2005)), then the simple rule of Proposition 1 takes on an additional term, and attenuation of the victims' ex-ante uncertainty becomes relatively more desirable.

- Insurance. In the model, parties have no access to private insurance. Would results change if private insurance were available? The answer tends to be negative. Insurance policies come with a loading factor, covering administrative costs, usually in the amount of $30-50 \%$ of the premium. Given a positive loading factor, optimal insurance contracts contain deductibles. Because of this, some risk remains on the parties. Thus, attenuation remains desirable.

\footnotetext{
${ }^{27}$ Appendix A4 develops a simple sufficient condition for the dominance of regulation. This condition states that the payment of damages in addition to precaution costs increases the size of the ex-ante risk faced by the injurer. Under an Arrow-Pratt approximation, this condition is met if precuation costs and damages are not negatively correlated.

${ }^{28}$ See Gilboa and Marinacci (2013) for an introduction to the literature on ambiguity aversion. The impact of ambiguity aversion on liability law has been explored, among others, by Teitelbaum (2007) and Franzoni (2017).
} 
- Countercyclical regulation. Note, finally, that in the model, parties' income is kept constant across states. In other words, variations in the parties' payoffs are due only to changes in the "fundamentals" (precaution costs and probability of harm). It is clear that policy decision making could also provide individuals with (partial) insurance against income fluctuations. For instance, regulation could become softer when injurers are subject to a strong negative income shock while victims are not, and vice versa. ${ }^{29}$ Here, however, the question of why insurance is not provided through the tax system becomes more compelling. ${ }^{30}$

\section{Final remarks}

The uncertainty of the timing and scope of new legal rules has long been a major cause for concern in the business community. More recently, this concern has been amplified by climate change. As the global temperature increases, additional mitigation policies are likely to be adopted that might cause the dismay of entire industries (and the joy of others). The scope and timing of these measures, however, remain extremely hard to predict due to the compound effects of political, natural, and scientific uncertainty (see IPCC (2014)). Law makers cannot ignore the huge costs produced by such uncertainty.

This paper has investigated a specific tool that can be used to provide insurance to the parties affected by policy making, at little or no cost. This tool, first proposed by Steven Shavell, prescribes that policy decisions be distorted at the margin to attenuate the ex-ante risk borne by the parties. In the model developed in this paper, the attenuation policy is applied to regulatory standards, liability law, and corrective taxation. In all three cases, attenuation increases social welfare.

\footnotetext{
${ }^{29}$ This would represent a form of "countercyclical regulation" (see Masur and Posner (2017)). Fagan (2017) studies efficiency-enhancing (legal) stabilization rules.

${ }^{30}$ In a sense, attenuation provides a "local" solution to the insurance issue, as relief is offered by changing, at the margin, the level of welfare of the parties affected by the policy decision (injurers and victims). Taxes could provide instead a "global" solution, as they can distribute risk over all members of society. The global solution tends to be theoretically preferable. It might fail, however, when the "local" problem is large enough. Correlated risks affecting a large section of the population cannot be perfectly spread.
} 
In general, the direction in which conventional policies should be changed depends on the sign of the shock parties are subject to (negative or positive), the size of the shock, and their disposition towards risk. These factors interact in a simple way. Their estimation requires little information. The corrective taxation case is somewhat more complicated because, here, the direction of change depends on the elasticity of precaution with respect to the tax rate.

The analysis of decision making under uncertainty developed in this paper is complementary to the classic analysis in Weitzman (1974)'s tradition (at the basis of current environmental policy). The latter emphasizes the costs of making policy decisions when the information is not yet available; my analysis emphasizes the costs attendant with an unpredictable evolution of economic and environmental factors. In the latter perspective, the comparison of the different policy instruments is based not on their ability to contain the costs of mistakes, but on their ability to provide parties with partial insurance against uncertainty. Depending on the parties' ability to tolerate risk, and the size of the risk they are subject to, one instrument or another may be preferable.

The analysis of this paper leaves many important issues aside. Among these, I should mention that it does not consider durable precautions (which are relevant if uncertainty unfolds gradually and the law is subject to repeated changes). By contrast, given its basic nature, it can be applied to a very large number of instances: essentially, to all policy decisions based on cost-benefit analysis. 


\section{Appendix}

A1. Regulatory standards. The optimal standards are obtained by maximizing the expected utility of the injurer given the expected utility of the victims (there are $n_{V} / n_{I}=n$ victims per injurer), that is from ${ }^{31}$

$$
\begin{aligned}
\max _{x_{0}, x_{1}} E U_{I}\left(x_{0}, x_{1}\right) & =q u\left(y_{I}-n t-c_{0}\left(x_{0}\right)\right)+(1-q) u\left(y_{I}-n t-c_{1}\left(x_{1}\right)\right) \\
& \text { subject to } \\
E U_{V}\left(x_{0}, x_{1}\right) & =q\left[\left(1-p_{0}\left(x_{0}\right)\right) v\left(y_{V}+t\right)+p_{0}\left(x_{0}\right) v\left(y_{V}+t-h\right)\right]+ \\
& (1-q)\left[\left(1-p_{1}\left(x_{1}\right)\right) v\left(y_{V}+t\right)+p_{1}\left(x_{1}\right) v\left(y_{V}+t-h\right)\right] \\
& =q\left[\widehat{E U}_{0}^{V}\left(x_{0}\right)\right]+(1-q)\left[\widehat{E U}_{1}^{V}\left(x_{1}\right)\right]=r .
\end{aligned}
$$

$y_{I}$ and $\mathrm{y}_{V}$ are, respectively, the income levels of injurer and victims, $r$ is the reference expected utility level of each victim, and $t$ a money transfer from the injurer to each victim (which removes distributional concerns from the picture). The transfer takes place before uncertainty unravels.

Let us focus on the victims' expected utility. Figure 3 illustrates (in the diagram the index $\mathrm{V}$ is omitted).

\footnotetext{
${ }^{31}$ I am grateful to Steven Shavell for having encouraged me to formalize this part of the paper.
} 


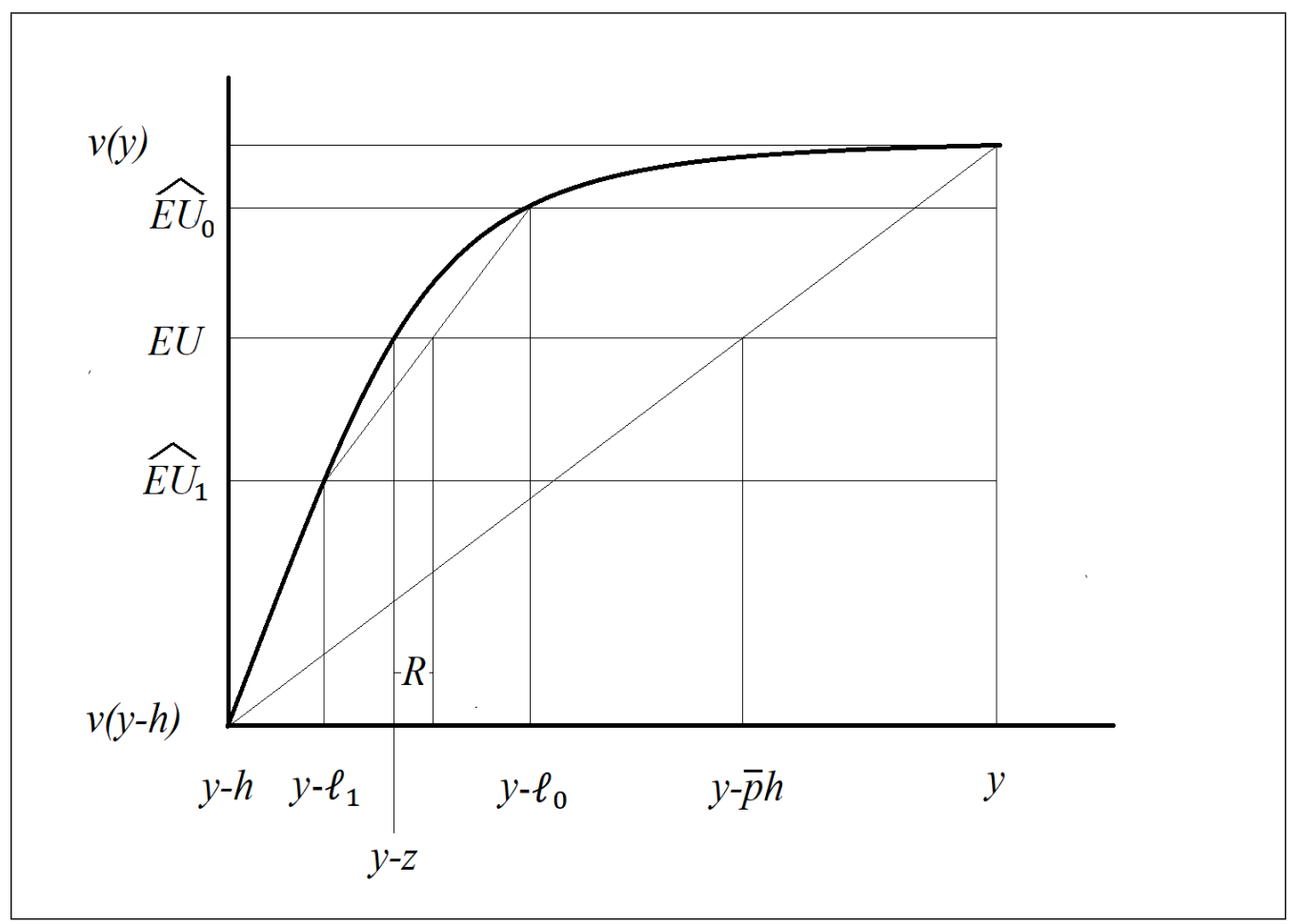

Fig. 3. Victim's utility function.

When the probability of harm is $p_{0}\left(x_{0}\right)$, the expected utility of the victim is $\widehat{E U}_{0}^{V}\left(x_{0}\right)$, and the certainty equivalent is $y_{V}-\ell_{0}\left(x_{0}\right)=y_{V}-p_{0}\left(x_{0}\right) h-R P_{0}^{V}\left(x_{0}\right)$. The certainty equivalent includes the expected loss $p_{0}\left(x_{0}\right) h$ and the risk premium $R P_{0}^{V}\left(x_{0}\right)$ due to the uncertainty about the occurrence of harm. When the probability of harm is $p_{1}\left(x_{1}\right)$, the expected utility is $\widehat{E U}_{1}^{V}\left(x_{1}\right)$, and the certainty equivalent is $y_{V}-\ell_{1}\left(x_{1}\right)=y_{V}-p_{1}\left(x_{1}\right)-$ $R P_{1}^{V}\left(x_{1}\right)$.

From (14), it is clear that the ex-ante expected utility $E U_{V}\left(x_{0}, x_{1}\right)$ is equal to the expected utility associated to the compound probability of harm $\bar{p}=q p_{0}\left(x_{0}\right)+(1-q) p_{1}\left(x_{1}\right)$. The certainty equivalent of $E U_{V}\left(x_{0}, x_{1}\right)$ is $y_{V}-z$.

Figure 3 shows that $y_{V}-z$ can also be obtained as the certainty equivalent of a lottery in which the victim's income is $y_{V}-\ell_{0}\left(x_{0}\right)$ with probability $q$, and $y_{V}-\ell_{1}\left(x_{1}\right)$ with probability $1-q$. Specifically, $y_{V}-z=y_{V}-q \ell_{0}\left(x_{0}\right)-(1-q) \ell_{1}\left(x_{1}\right)-R_{V}$, where $R_{V}$ is the risk premium due to the ex-ante uncertainty about the probability of harm. Note that $R_{V}$ increases if $\ell_{0}$ decreases and if $\ell_{1}$ increases. Given $\ell_{1}$ and $\ell_{0}, R_{V}$ increases if $v$ is subject to a concave 
monotone transformation.

In view of the previews observations, constraint (15) can be reformulated as

$$
E U_{V}\left(x_{0}, x_{1}\right)=v\left(y_{V}+t-q \ell_{0}\left(x_{0}\right)-(1-q) \ell_{1}\left(x_{1}\right)-R_{V}\right)=r
$$

or

$$
y_{V}+t-q \ell_{0}\left(x_{0}\right)-(1-q) \ell_{1}\left(x_{1}\right)-R_{V}=v^{-1}(r) .
$$

Also the payoff of the injurer can be formulated in terms of a certainty equivalent. Maximization (13) can be written as

$$
\begin{gathered}
\max _{x_{0}, x_{1}} E U_{I}\left(x_{0}, x_{1}\right)=u\left(y_{I}-n t-q c_{0}\left(x_{0}\right)-(1-q) c_{1}\left(x_{1}\right)-R_{I}\right) \\
\text { subject to eq. }(17),
\end{gathered}
$$

where $R_{I}$ is the risk premium due to the uncertainty about the precaution costs. Substituting $t$ from (17) into (18) yields (omitting arguments):

$$
\max _{x_{0}, x_{1}} u\left(y_{I}-q c_{0}-(1-q) c_{1}-R_{I}+n\left(y_{V}-q \ell_{0}-(1-q) \ell_{1}-R_{V}-v^{-1}(r)\right)\right),
$$

which is equivalent to

$$
\max _{x_{0}, x_{1}} y_{I}-q c_{0}-(1-q) c_{1}-R_{I}+n\left(y_{V}-q \ell_{0}-(1-q) \ell_{1}-R_{V}-v^{-1}(r)\right)
$$

since $u$ is a positive monotone transformation of its argument (the slope of $u(f(x))$ has the same sign as the slope of $f(x))$.

Since, $v^{-1}(r)$ is a constant, (19) is equivalent to

$$
\begin{aligned}
& \max _{x_{0}, x_{1}} W^{\text {ex-ante }}\left(x_{0}, x_{1}\right)=y_{I}-q c_{0}-(1-q) c_{1}-R_{I}+n\left[y_{V}-q \ell_{0}-(1-q) \ell_{1}-R_{V}\right] \\
& =q\left[y_{I}-c_{0}+y_{V}-q \ell_{0}\right]+(1-q)\left[y_{I}-c_{1}+n\left(y_{V}-(1-q) \ell_{1}\right)\right]-R_{I}-n R_{V} \\
& =q \widehat{W}_{0}\left(x_{0}\right)+(1-q) \widehat{W}_{1}\left(x_{1}\right)-R_{I}-n R_{V},
\end{aligned}
$$

where $\widehat{W}_{0}\left(x_{0}\right)$ and $\widehat{W}_{1}\left(x_{1}\right)$ are the ex-post welfare levels (as in eq.(6) of Section 3 ).

The assumptions about the cost functions and the probabilities of harm guarantee that the optimal standards lie in the interior. I further assume that $W\left(x_{0}, x_{1}\right)$ is strictly quasi-convex. 
We have

$$
\frac{\partial W^{e x-\text { ante }}\left(x_{0}, x_{1}\right)}{\partial x_{0}}=q \frac{\partial \widehat{W}_{0}\left(x_{0}\right)}{\partial x_{0}}-\frac{\partial R_{I}}{\partial c_{0}\left(x_{0}\right)} c_{0}^{\prime}\left(x_{0}\right)-n \frac{\partial R_{V}}{\partial \ell_{0}\left(x_{0}\right)} \ell_{0}^{\prime}\left(x_{0}\right) .
$$

At $x_{0}=x_{0}^{c}, x_{1}=x_{1}^{c}$, we have $\frac{\partial \widehat{W}_{0}\left(x_{0}\right)}{\partial x_{0}}=0$ and $c_{0}^{\prime}\left(x_{0}^{c}\right)=-n \ell_{0}^{\prime}\left(x_{0}^{c}\right)$ (from 3$)$, so:

$$
\frac{\partial W^{e x-a n t e}\left(x_{0}^{c}, x_{1}^{c}\right)}{\partial x_{0}}>0 \Leftrightarrow \frac{\partial R_{I}}{\partial c_{0}\left(x_{0}^{c}\right)}<\frac{\partial R_{V}}{\partial \ell_{0}\left(x_{0}^{c}\right)} .
$$

Similarly, we get

$$
\frac{\partial W^{e x-a n t e}\left(x_{0}^{c}, x_{1}^{c}\right)}{\partial x_{1}}>0 \Leftrightarrow \frac{\partial R_{I}}{\partial c_{1}\left(x_{1}^{c}\right)}<\frac{\partial R_{V}}{\partial \ell_{1}\left(x_{1}^{c}\right)} .
$$

A2. Optimal damages. Let us consider the problem of Section 4. We have

$$
\ell_{0}^{I}\left(x_{0}\right)=c_{0}\left(x_{0}\right)+p_{0}\left(x_{0}\right) n d_{0}+R P_{0}^{I}\left(n d_{0}\right)
$$

where $R P_{0}^{I}\left(d_{0}\right)$ is the risk premium attendant with the prospect of bearing liability $n d_{0}$ with probability $p_{0}\left(x_{0}\right)$. The level of care $x_{0}^{I}$ is decided by the injurer to minimize her cost of harm: $x_{0}^{I}=\arg \min _{x_{0}}\left(\ell_{0}^{I}\left(x_{0}\right)\right)$, and thus ${ }^{32}$

$$
c_{0}^{\prime}\left(x_{0}^{c}\right)=-\left[p_{0}^{\prime}\left(x_{0}\right) n d_{0}+\frac{\partial R P_{0}^{I}\left(n d_{0}\right)}{\partial x_{0}}\right] .
$$

The costs of harm for each victim is:

$$
\ell_{0}^{V}\left(x_{0}^{I}\right)=p_{0}\left(x_{0}^{I}\right)\left(h-d_{0}\right)+R P_{0}^{V}\left(h-d_{0}\right)
$$

where $R P_{0}^{V}\left(h-d_{0}\right)$ is the risk premium attendant with the prospect of bearing uncompensated harm $h-d_{0}$ with probability $p_{0}\left(x_{0}^{I}\right)$. One can easily see that the cost of harm increases if $h-d_{0}$ increases and if $p_{0}\left(x_{0}^{I}\right)$ decreases. Furthermore, it can be shown (using the definition of the risk premium), that $R P_{0}^{V}\left(h-d_{0}\right)=0$ and $\frac{\partial R P_{0}^{V}\left(h-d_{0}\right)}{\partial\left(h-d_{0}\right)}=0$ if $d_{0}=h$.

The optimal conventional level of damages can be found by maximizing social welfare (per

${ }^{32}$ The impact of an increase in $n d_{0}$ on $x_{0}^{I}$ is generally ambiguous (it is positive, however, if risk-aversion is not decreasing in income - see Sweeney and Beard (1992)). 
injurer):

$$
W_{0}^{S L}\left(d_{0}\right)=y_{I}-\ell_{0}^{I}\left(x_{0}^{I}\right)+n\left[y_{V}-\ell_{0}^{V}\left(x_{0}^{I}\right)\right]
$$

We have

$$
\frac{W_{0}^{S L}\left(d_{0}\right)}{\partial d_{0}}=-\frac{\partial \ell_{0}^{I}\left(x_{0}^{I}\right)}{\partial x_{0}^{I}} \frac{\partial x_{0}^{I}}{\partial d_{0}}-\left.\frac{\partial \ell_{0}^{I}\left(x_{0}^{I}\right)}{\partial d_{0}}\right|_{x=x_{0}^{I}}-n \frac{\partial \ell_{0}^{V}\left(x_{0}^{I}\right)}{\partial x_{0}^{I}} \frac{\partial x_{0}^{I}}{\partial d_{0}}-\left.n \frac{\partial \ell_{0}^{V}\left(x_{0}^{I}\right)}{\partial d_{0}}\right|_{x=x_{0}^{I}}
$$

with $\frac{\partial \ell_{0}^{I}\left(x_{0}^{I}\right)}{\partial x_{0}^{I}}=0$ because of the optimality of $x_{0}^{I}$.

Note that

$$
\left.\frac{\partial \ell_{0}^{I}\left(x_{0}^{I}\right)}{\partial d_{0}}\right|_{x=x_{0}^{I}}=p_{0}\left(x_{0}^{I}\right) n+\frac{\partial R P_{0}^{I}\left(n d_{0}\right)}{\partial d_{0}},\left.\frac{\partial \ell_{0}^{V}\left(x_{0}^{I}\right)}{\partial d_{0}}\right|_{x=x_{0}^{I}}=-p_{0}\left(x_{0}^{I}\right)+\frac{\partial R P_{0}^{V}\left(n d_{0}\right)}{\partial d_{0}}
$$

and

$$
\frac{\partial \ell_{0}^{V}\left(x_{0}^{I}\right)}{\partial x_{0}^{I}} \frac{\partial x_{0}^{I}}{\partial d_{0}}=\frac{\partial x_{0}^{I}}{\partial d_{0}} \frac{\partial p_{0}\left(x_{0}^{I}\right)}{\partial x_{0}^{I}}\left[h-d_{0}+\frac{\partial R P_{0}^{V}\left(h-d_{0}\right)}{\partial p_{0}\left(x_{0}^{I}\right)}\right] .
$$

Thus, upon simplification,

$$
\frac{W_{0}^{S L}\left(d_{0}\right)}{\partial d_{0}}=-\frac{\partial R P_{0}^{I}\left(n d_{0}\right)}{\partial d_{0}}-n \frac{\partial R P_{0}^{V}\left(n d_{0}\right)}{\partial d_{0}}-n \frac{\partial x_{0}^{I}}{\partial d_{0}} \frac{\partial p_{0}\left(x_{0}^{I}\right)}{\partial x_{0}^{I}}\left[h-d_{0}+\frac{\partial R P_{0}^{V}\left(h-d_{0}\right)}{\partial p_{0}\left(x_{0}^{I}\right)}\right]
$$

For $d_{0}=h$, the last two terms boil down to nil. An increase in damages does not affect the payoff of the victims because: i) they can perfectly bear small risks (for very small losses, risk-averse agents behave as risk neutral ones), ii) they do not suffer from an increase in the probability of harm because they are perfectly compensated.

Thus,

$$
\frac{W_{0}^{S L}(h)}{\partial d_{0}}=-\frac{\partial R P_{0}^{I}(n h)}{\partial d_{0}}<0
$$

This proves that optimal conventional damages are under-compensatory $\left(d_{0}^{c}<h\right)$. The same applies to $d_{1}^{c}$.

Let us now see if the same argument applies in the presence of ex-ante uncertainty. From (8), we get: 


$$
\frac{\partial W^{\text {ex-ante }}\left(d_{0}, d_{1}\right)}{\partial d_{0}}=q \frac{W_{0}^{S L}\left(d_{0}\right)}{\partial d_{0}}-\frac{\partial R_{I}}{\partial \ell_{0}^{I}\left(x_{0}^{I}\right)} \frac{\partial \ell_{0}^{I}\left(x_{0}^{I}\right)}{\partial d_{0}}-n \frac{\partial R_{V}}{\partial \ell_{0}^{V}\left(x_{0}^{V}\right)} \frac{\partial \ell_{0}^{V}\left(x_{0}^{I}\right)}{\partial d_{0}}
$$

For $d_{0}=h$, we have $\frac{\partial \ell_{0}^{V}\left(x_{0}^{I}\right)}{\partial d_{0}}=0$. Thus, using $(22)$

$$
\begin{aligned}
\frac{\partial W^{\text {ex-ante }}\left(h, d_{1}\right)}{\partial d_{0}} & <0 \\
& \Longleftrightarrow-q \frac{\partial R P_{0}^{I}(n h)}{\partial d_{0}}-\frac{\partial R_{I}}{\partial \ell_{0}^{I}\left(x_{0}^{I}\right)} \frac{\partial \ell_{0}^{I}\left(x_{0}^{I}\right)}{\partial d_{0}}<0 \\
& \Longleftrightarrow-\frac{\partial R_{I}}{\partial \ell_{0}^{I}\left(x_{0}^{I}\right)}\left[p_{0}\left(x_{0}^{I}\right) n+\frac{\partial R P_{0}^{I}(n h)}{\partial d_{0}}\right]<q \frac{\partial R P_{0}^{I}(n h)}{\partial d_{0}} .
\end{aligned}
$$

with $p_{0}\left(x_{0}^{I}\right) n+\frac{\partial R P_{0}^{I}(n h)}{\partial d_{0}}>0$.

Inequality (23) might not be met. In particular, if state 0 represents the good state for the injurer (i.e., $\left.\ell_{0}^{I}\left(x_{0}^{I}\right)<\ell_{1}^{I}\left(x_{1}^{I}\right)\right)$, so that $\frac{\partial R_{I}}{\partial \ell_{0}^{I}\left(x_{0}^{I}\right)}<0$, and it occurs with small probability (small $q$ ), then over-compensatory damages are optimal.

A3. Optimal corrective tax. Given the optimal conventional tax rates $t_{0}^{c}$ and $t_{1}^{c}$, we get (from 12):

$$
\frac{\partial W^{\text {ex-ante }}\left(t_{0}^{c}, t_{1}^{c}\right)}{\partial t_{0}}=q \frac{\partial \widehat{W}_{0}\left(t_{0}\right)}{\partial t_{0}}-\frac{\partial R_{I}}{\partial \ell_{0}^{I}\left(x_{0}^{I}\right)} \frac{\partial \ell_{0}^{I}\left(x_{0}^{I}\right)}{\partial t_{0}}-n \frac{\partial R_{V}}{\partial \ell_{0}^{V}\left(x_{0}^{I}\right)} \frac{\partial \ell_{0}^{V}\left(x_{0}^{I}\right)}{\partial t_{0}}
$$

Thus, from (10), (10) and (11) :

$$
\begin{aligned}
& \frac{\partial W^{\text {ex-ante }}\left(t_{0}^{c}, t_{1}^{c}\right)}{\partial t_{0}}>0 \Leftrightarrow \frac{\partial R_{I}}{\partial \ell_{0}^{I}\left(x_{0}^{I}\right)}\left(X-x_{0}^{I}\right)<-\frac{\partial R_{V}}{\partial \ell_{0}^{V}\left(x_{0}^{I}\right)} \frac{\partial x_{0}^{I}}{\partial t_{0}} n \ell_{0}^{V \prime}\left(x_{0}^{I}\right) \Leftrightarrow \\
& \frac{\partial R_{I}}{\partial \ell_{0}^{I}\left(x_{0}^{I}\right)}\left(X-x_{0}^{I}\right)<\frac{\partial R_{V}}{\partial \ell_{0}^{V}\left(x_{0}^{I}\right)} \frac{\partial x_{0}^{I}}{\partial t_{0}} t_{0}^{c} \Leftrightarrow \frac{\partial R_{I}}{\partial \ell_{0}^{I}\left(x_{0}^{I}\right)} \frac{X-x_{0}^{I}}{x_{0}^{I}}<\frac{\partial R_{V}}{\partial \ell_{0}^{V}\left(x_{0}^{I}\right)} \varepsilon_{t_{0}}^{x_{0}} .
\end{aligned}
$$

A4. Choice of instrument. Let us first compare regulation and corrective taxation. Under regulation, ex-ante social welfare is:

$$
\begin{aligned}
W_{\text {reg }}^{\text {ex-ante }}\left(x_{0}^{R}, x_{1}^{R}\right) & =y_{I}-q c_{0}\left(x_{0}^{R}\right)-(1-q) c_{1}\left(x_{1}^{R}\right)-R_{I}^{r e g} \\
& +n\left[y_{V}-q \ell_{0}^{V}\left(x_{0}^{R}\right)-(1-q) \ell_{1}^{V}\left(x_{1}^{R}\right)-R_{V}^{r e g}\right] .
\end{aligned}
$$


Under taxation, ex-ante social welfare is

$$
\begin{gathered}
W_{\text {tax }}^{e x-\text { ante }}\left(x_{0}^{T}, x_{1}^{T}\right)=y_{I}-q c_{0}\left(x_{0}^{T}\right)-(1-q) c_{1}\left(x_{1}^{T}\right)-R_{I}^{\text {tax }} \\
+n\left[y_{V}-q \ell_{0}^{V}\left(x_{0}^{T}\right)-(1-q) \ell_{1}^{V}\left(x_{1}^{T}\right)-R_{V}^{t a x}\right] .
\end{gathered}
$$

Suppose that, under regulation, the policymaker selects standards equal to the level of precaution arising under optimal taxes. Upon simplification, we get:

$$
W_{\text {reg }}^{\text {ex-ante }}\left(x_{0}^{T}, x_{1}^{T}\right)>W_{\text {tax }}^{\text {ex-ante }}\left(x_{0}^{T}, x_{1}^{T}\right) \Longleftrightarrow R_{I}^{\text {reg }}<R_{I}^{\text {tax }}
$$

Note that, here, victims are not affected by the instrument choice. The two ex-ante risk premiums, $R_{I}^{r e g}$ and $R_{I}^{t a x}$, can differ for a variety or reasons, including the net income level available to injurers. To remove income effects, let us consider an Arrow-Pratt second order approximation. We get:

$$
\begin{aligned}
R_{I}^{r e g} & <R_{I}^{\operatorname{tax}} \Longleftrightarrow \operatorname{Var}(c)<\operatorname{Var}(c+T) \\
& \Longleftrightarrow \operatorname{Var}(c)<\operatorname{Var}(c)+\operatorname{Var}(T)+2 \operatorname{Cov}(c, T) \\
& \Longleftrightarrow \operatorname{Cov}(c, T)>-\frac{1}{2} \operatorname{Var}(T)
\end{aligned}
$$

The last inequality is surely met if precaution costs and tax payments are non negatively correlated. Under this condition, $W_{\text {reg }}^{\text {ex-ante }}\left(x_{0}^{T}, x_{1}^{T}\right)>W_{\text {tax }}^{\text {ex-ante }}\left(x_{0}^{T}, x_{1}^{T}\right)$. So a fortiori, regulation dominates if the standards can be optimally set.

Let us now compare regulation and liability. Under liability, ex-ante social welfare is (omitting arguments)

$$
\begin{aligned}
& W_{\text {liab }}^{\text {ex-ante }}\left(d_{0}^{*}, d_{1}^{*}\right)=y_{I}-q\left(c_{0}+p_{0} n d_{0}^{*}+R P_{0}^{I}\right)-(1-q)\left(c_{1}+p_{1} n d_{1}^{*}+R P_{1}^{I}\right)-R_{I}^{\text {liab }} \\
& +n\left[y_{V}-q\left(p_{0}\left(h-d_{0}^{*}\right)+R P_{0}^{V}\right)-(1-q)\left(p_{1}\left(h-d_{1}^{*}\right)-R P_{1}^{V}\right)-R_{V}^{\text {liab }}\right],
\end{aligned}
$$

where $\left(d_{0}^{*}, d_{1}^{*}\right)$ are the optimal damages.

Regulation and liability generate risks of different types, both on injurers and victims, so a general comparison is hard to come by. If injurers are risk neutral and victims risk averse, strict liability with full compensation provides victims with full insurance and it yields the first best. Let us consider the case in which victims are risk neutral and injurers risk averse. Suppose now that the levels of precaution $x_{0}^{L}, x_{1}^{L}$ arising under optimal damages are used as 
standards in the regulation regime. We get

$$
\begin{aligned}
W_{\text {reg }}^{\text {ex-ante }}\left(x_{0}^{L}, x_{1}^{L}\right) & >W_{\text {liab }}^{\text {ex-ante }}\left(d_{0}^{*}, d_{1}^{*}\right) \Longleftrightarrow \\
R_{I}^{\text {reg }} & <q R P_{0}^{I}+(1-q) R P_{1}^{I}+R_{I}^{\text {liab }} .
\end{aligned}
$$

A sufficient condition for the latter inequality to hold is: $R_{I}^{r e g}<R_{I}^{\text {liab }}$. In other words, the payment of damages (under liability) in addition to precaution costs increases the ex-ante risk borne by the injurer. Using a second order approximation, we get

$$
\begin{aligned}
& R_{I}^{r e g}<R_{I}^{\text {liab }} \Longleftrightarrow \operatorname{Var}(c)<\operatorname{Var}\left(c+p d+R P_{I}\right) \\
& \Longleftrightarrow \operatorname{Var}(c)<\operatorname{Var}(c)+\operatorname{Var}\left(p d+R P_{I}\right)+2 \operatorname{Cov}\left(c, p d+R P_{I}\right), \\
& \Longleftrightarrow \operatorname{Var}\left(p d+R P_{I}\right)+2 \operatorname{Cov}\left(c, p d+R P_{I}\right)>0 .
\end{aligned}
$$

So, if $\operatorname{Cov}\left(c, p d+R P_{I}\right)>0$, we know that $R_{I}^{\text {reg }}<R_{I}^{\text {liab }}$ and regulation with constrained standards dominates liability. If the standards can be optimally set, the dominance is even stricter.

Using a similar argument, it can be shown that, with risk neutral victims, taxation (with an exogenous allowance $X$ ) dominates liability if

$$
\begin{aligned}
& R_{I}^{\operatorname{tax}}<R_{I}^{l i a b} \Longleftrightarrow \operatorname{Var}(c+T)<\operatorname{Var}\left(c+p d+R P_{I}\right) \\
& \Longleftrightarrow \operatorname{Var}(c)+\operatorname{Var}(T)+2 \operatorname{Cov}(c, T)<\operatorname{Var}(c)+\operatorname{Var}\left(p d+R P_{I}\right)+2 \operatorname{Cov}\left(c, p d+R P_{I}\right), \\
& \Longleftrightarrow \operatorname{Var}(T)+2 \operatorname{Cov}(c, T)<\operatorname{Var}\left(p d+R P_{I}\right)+2 \operatorname{Cov}\left(c, p d+R P_{I}\right) .
\end{aligned}
$$

Both taxation and liability produce variance that goes beyond precaution costs. In the latter inequality, the term on the LHS heavily depends on how the baseline level of precaution $X$ is fixed. Taxation dominates if: net tax payments (or subsidies) are small (and so presumably is their variance), tax payments are negatively correlated with precaution costs, liability costs are large (and so presumably their variance), and liability costs are positively correlated with precaution costs.

A5. Ambiguity aversion (regulatory standards). There are several models of ambiguity aversion. Here, I use one of the most general, the smooth model of Klibanoff et al. (2005), which posits that parties are averse to mean-preserving spreads of their beliefs.

The victims' ex-ante welfare can be written as 


$$
V^{A}=q \varphi\left(\widehat{E U}_{0}^{V}\left(x_{0}\right)\right)+(1-q) \varphi\left(\widehat{E U}_{1}^{V}\left(x_{1}\right)\right)
$$

where $\varphi$ is a concave monotone function. As with standard risk aversion, the concave transformation implies that the welfare derived from the two expected utilities is less than the mean value of the expected utilities. This implies that to know (or to conjecture) that the probability of harm will take value $p_{0}\left(x_{0}\right)$ with probability $q$ and value $p_{1}\left(x_{1}\right)$ with probability $(1-q)$ is worse than knowing for certain that the probability of harm will be $q p_{0}\left(x_{0}\right)+(1-q) p_{1}\left(x_{1}\right)$.

From (28), the uncertainty premium due to ambiguity, $R^{A}$, should meet

$$
\varphi\left(q \widehat{E U}_{0}^{V}\left(x_{0}\right)+(1-q) \widehat{E U}_{1}^{V}\left(x_{1}\right)-R^{A}\right)=V^{A}
$$

So, the level of welfare achieved by the victims can be seen as (a monotone transformation of) conventional expected utility minus an ambiguity premium. The ambiguity premium $R_{A}$ decreases if the wedge between $\ell_{0}\left(x_{0}\right)$ and $\ell_{1}\left(x_{1}\right)$ decreases.

In view of (16), the victim's welfare can be also written as

$$
V^{A}=\varphi\left(y_{V}-q \ell_{0}\left(x_{0}\right)-(1-q) \ell_{1}\left(x_{1}\right)-R_{V}-R^{A}\right) .
$$

So, the maximization of the welfare function $V^{A}$ is equivalent to the maximization of the ex-ante certainty equivalent $V^{\text {ex-ante: }}$

$$
\begin{aligned}
V^{e x-a n t e} & =y_{V}-q \ell_{0}\left(x_{0}\right)-(1-q) \ell_{1}\left(x_{1}\right)-R_{V}-R^{A} . \\
& =y_{V}-\widehat{\ell}_{V}^{e x-a n t e}\left(x_{0}, x_{1}\right) .
\end{aligned}
$$

Going through the same steps as before (Appendix A1), we get that the optimal ex-ante policy should maximize;

$$
\begin{aligned}
& W^{\text {ex-ante }}\left(x_{0}, x_{1}\right)=n_{I}\left[y_{I}-\ell_{I}^{e x-a n t e}\left(x_{0}, x_{1}\right)\right]+n_{V}\left[y_{I}-\widehat{\ell}_{V}^{e x-a n t e}\left(x_{0}, x_{1}\right)\right] \\
& =n_{I}\left[y_{I}-q c_{0}\left(x_{0}\right)-(1-q) c_{1}\left(x_{1}\right)-R_{I}\right]+n_{V}\left[y_{I}-q \ell_{0}\left(x_{0}\right)-(1-q) \ell_{1}\left(x_{1}\right)-R_{V}-R^{A}\right] \\
& =q \widehat{W}_{0}\left(x_{0}\right)+(1-q) \widehat{W}_{1}\left(x_{1}\right)-n_{I} R_{I}-n_{V}\left(R_{V}+R^{A}\right) .
\end{aligned}
$$


Thus

$$
\frac{\partial W^{e x-a n t e}\left(x_{0}, x_{1}\right)}{\partial x_{0}}=q \widehat{W}_{0}^{\prime}\left(x_{0}\right)-n_{I} \frac{\partial R_{I}}{\partial c_{0}\left(x_{0}\right)} c_{0}^{\prime}\left(x_{0}\right)-n_{V} \frac{\partial\left(R_{V}+R^{A}\right)}{\partial \ell_{0}\left(x_{0}\right)} \ell_{0}^{\prime}\left(x_{0}\right) .
$$

At $x_{0}=x_{0}^{c}, x_{1}=x_{1}^{c}$, (using $\widehat{W}_{0}^{\prime}\left(x_{0}\right)=0$ and $n_{I} c_{0}^{\prime}\left(x_{0}^{c}\right)=-n_{V} \ell_{0}^{\prime}\left(x_{0}^{c}\right)$ ), we get

$$
\frac{\partial W^{e x-a n t e}\left(x_{0}^{c}, x_{1}^{c}\right)}{\partial x_{0}}<0 \Leftrightarrow \frac{\partial R_{I}}{\partial c_{0}\left(x_{0}^{c}\right)}>\frac{\partial R_{V}}{\partial \ell_{0}\left(x_{0}^{c}\right)}+\frac{\partial R^{A}}{\partial \ell_{0}\left(x_{0}^{c}\right)} .
$$

Both $R_{V}$ and $R^{A}$ increase as the wedge between $\ell_{0}\left(x_{0}\right)$ and $\ell_{1}\left(x_{1}\right)$ increases. So, the addendum $\frac{\partial R^{A}}{\partial \ell_{0}\left(x_{0}^{c}\right)}$ just amplifies the benefit of uncertainty attenuation for the victims. 


\section{References}

Aldy, J. E. (2017). The political economy of carbon pricing policy design. Technical Report ES 17-7, Harvard Project on Climate Agreements.

Aldy, J. E. and W. K. Viscusi (2014). Environmental risk and uncertainty. In Handbook of the Economics of Risk and Uncertainty, Volume 1, pp. 601-649. Elsevier.

Blume, L. and D. L. Rubinfeld (1984). Compensation for takings: an economic analysis. California Law Review 72(4), 569-628.

Breyer, S. (2009). Breaking the Vicious Circle: Toward Effective Risk Regulation. Cambridge MA: Harvard University Press.

Dari-Mattiacci, G. and L. A. Franzoni (2014). Innovative negligence rules. American Law and Economics Review 16(2), 333-365.

EC (2017). Better Regulation Guidelines. European Commission, Brussel.

EPA (2016). Technical Guidance for Assessing Environmental Justice in Regulatory Analysis. U.S. Environmental Protection Agency, Washington.

Fagan, F. (2017). Legal cycles and stabilization rules. In F. Fagan and S. Levmore (Eds.), The Timing of Lawmaking. Edward Elgar Publishing.

Feldstein, M. (1976). On the theory of tax reform. Journal of Public Economics 6(1-2), $77-104$.

Franzoni, L. A. (2016). Correlated accidents. American Law and Economics Review 18(2), $358-384$.

Franzoni, L. A. (2017). Liability law under scientific uncertainty. American Law and Economics Review 19(2), 327-360.

Gilboa, I. and M. Marinacci (2013). Ambiguity and the Bayesian paradigm. In D. Acemoglu, M. Arellano, and E. Dekel (Eds.), Advances in Economics and Econometrics, 10th World Congress. Cambridge University Press. 
Graetz, M. J. (1977). Legal transitions: The case of retroactivity in income tax revision. University of Pennsylvania Law Review 126, 47-87.

IPCC (2014). Mitigation of Climate Change. Cambridge University Press, Cambridge, UK and New York, NY.

IPCC (2018). Global Warming of 1.5Âr. Cambridge University Press, Cambridge, UK and New York, NY.

Jullien, B., B. Salanié, and F. Salanié (1999). Should More Risk-Averse Agents Exert More Effort? The Geneva Papers on Risk and Insurance Theory 24(1), 19-28.

Kaplow, L. (1986). An economic analysis of legal transitions. Harvard Law Review 99, 509617.

Kaplow, L. and S. Shavell (2002). On the superiority of corrective taxes to quantity regulation. American Law and Economics Review 4(1), 1-17.

Klibanoff, P., M. Marinacci, and S. Mukerji (2005). A smooth model of decision making under ambiguity. Econometrica 73(6), 1849-1892.

Kolstad, C. D., T. S. Ulen, and G. V. Johnson (1990). Ex post liability for harm vs. ex ante safety regulation: substitutes or complements? The American Economic Review 80(4), 888-901.

Levmore, S. (1999). Changes, anticipations, and reparations. Columbia Law Review 99, $1657-1700$.

Masur, J. S. and J. R. Nash (2010). The institutional dynamics of transition relief. New York University Law Review 85, 101-162.

Masur, J. S. and E. A. Posner (2017). Should regulation be countercyclical? Yale Journal on Regulation 34, 857-893.

Michelman, F. I. (1967). Property, utility, and fairness: Comments on the ethical foundations of "just compensation" law. Harvard Law Review 80, 1165-1258. 
Nash, J. R. and R. L. Revesz (2007). Grandfathering and environmental regulation: The law and economics of new source review. Northwestern University Law Review 101, 1677-1732.

Parisi, F. and V. Fon (2009). The Economics of Lawmaking. Oxford University Press.

Samuelson, P. A. (1952). Probability, utility, and the independence axiom. Econometrica $20(4), 670-678$.

Shavell, S. (1982). On liability and insurance. The Bell Journal of Economics 13(1), 120-132.

Shavell, S. (2008). On optimal legal change, past behavior, and grandfathering. The Journal of Legal Studies 37(1), 37-85.

Shavell, S. (2014a). A general rationale for a governmental role in the relief of large risks. Journal of Risk and Uncertainty 49(3), 213-234.

Shavell, S. (2014b). Risk aversion and the desirability of attenuated legal change. American Law and Economics Review 16(2), 366-402.

Shaviro, D. (2000). When Rules Change: The Economics of Retroactivity. University of Chicago Press.

Sweeney, G. H. and T. R. Beard (1992). The comparative statics of self-protection. Journal of Risk and Insurance 59, 301-309.

Teitelbaum, J. (2007). A unilateral accident model under ambiguity. Journal Legal Studies $36(2), 431-477$.

Trebilcock, M. J. (2014). Dealing with Losers: the Political Economy of Policy Transitions. Oxford University Press, USA.

Weitzman, M. L. (1974). Prices vs. quantities. The Review of Economic Studies 41(4), 477-491. 


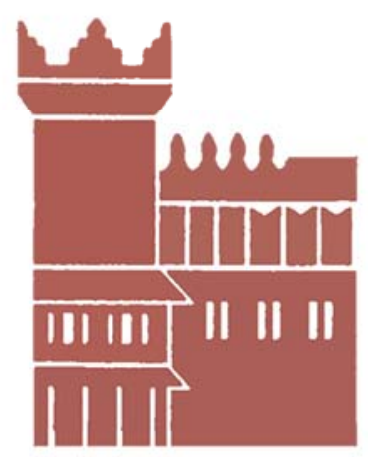

Alma Mater Studiorum - Università di Bologna DEPARTMENT OF ECONOMICS

Strada Maggiore 45

40125 Bologna - Italy

Tel. +39051 2092604

Fax +390512092664

http://www.dse.unibo.it 